\title{
Quantitative ultrastructural analysis of basket and axo-axonic cell terminals in the mouse hippocampus
}

\author{
Authors: Virág T. Takács, András Szőnyi, Tamás F. Freund, Gabor Nyiri *, Attila I. Gulyás * \\ Affiliations: Laboratory of Cerebral Cortex Research, Department of Cellular and Network Neurobiology, \\ Institute of Experimental Medicine, Hungarian Academy of Sciences, H-1083 Budapest, Hungary \\ * these authors contributed equally to this work \\ Corresponding author: \\ Gabor Nyiri \\ e-mail: nyiri.gabor@koki.mta.hu
}

\begin{abstract}
Three functionally different populations of perisomatic interneurons establish GABAergic synapses on hippocampal pyramidal cells: parvalbumin (PV)-containing basket cells, type 1 cannabinoid receptor $\left(\mathrm{CB}_{1}\right)$ positive basket cells both of which target somata, and PV-positive axo-axonic cells that innervate axon initial segments. Using electron microscopic reconstructions, we estimated that a pyramidal cell body receives synapses from about 60 and 140 synaptic terminals in the CA1 and CA3 area, respectively. About $60 \%$ of these terminals were PV-positive, whereas $35-40 \%$ of them were $\mathrm{CB}_{1}$-positive. Only about $1 \%$ (CA1) and $4 \%$ (CA3) of the somatic boutons were negative for both markers. Using fluorescent labeling, we showed that most of the $\mathrm{CB}_{1}$ positive terminals expressed vesicular glutamate transporter 3 . Reconstruction of somatic boutons revealed that although their volumes are similar, $\mathrm{CB}_{1}$-positive boutons are more flat and the total volume of their mitochondria was smaller than that of PV-positive boutons. Both types of boutons contain dense core vesicles and frequently formed multiple release sites on their targets and innervated an additional soma or dendrite as well. PV-positive boutons possessed small, macular synapses; whereas the total synaptic area of $\mathrm{CB}_{1}$-positive boutons was larger and formed multiple irregular shaped synapses. Axo-axonic boutons were smaller than somatic boutons, had only one synapse and their ultrastructural parameters were closer to those of PV-positive somatic boutons. Our results represent the first quantitative measurement -using a highly reliable method- of the contribution of different cell types to the persomatic innervation of pyramidal neurons, and may help to explain functional differences in their output properties.
\end{abstract}

Keywords (4-6): inhibitory neurons; synaptic convergence; active zone; three-dimensional reconstruction; immunogold 


\section{Introduction}

The hippocampal formation of the mammalian brain has a critical role in learning and memory, and plays important roles in several related processes as well. Its main output neurons are the pyramidal cells, the activity of which are precisely regulated by at least 18 different types of GABAergic interneurons that target partly nonoverlapping membrane domains (Klausberger and Somogyi, 2008). Among these cells, perisomatic interneurons specifically target the cell body and adjacent cell membranes of large populations of local principal cells, whereby they control and synchronize their spike output and, as a consequence, significantly determine hippocampal network activity (Cobb et al., 1995; Miles et al., 1996; Ellender et al., 2010). Perisomatic interneurons can be divided into three nonoverlapping and functionally different populations: two types of basket cells target the somatic and proximal dendritic region of principal cells and interneurons (Freund and Katona, 2007; Armstrong and Soltesz, 2012; Bartos and Elgueta, 2012), while axo-axonic cells innervate the axon initial segment (AIS) of principal cells (Somogyi, 1977).

One of the two basket cell types contains the calcium-binding protein parvalbumin (PV) (Katsumaru et al., 1988) and displays fast, non-accommodating firing patterns (Pawelzik et al., 2002).

The other type of basket cells expresses the neuropeptide cholecystokinin (CCK) (Nunzi et al., 1985) and type 1 cannabinoid receptor $\left(\mathrm{CB}_{1}\right)$ presynaptically (Katona et al., 1999), and unlike PV positive cells, $\mathrm{CCK} / \mathrm{CB}_{1}$ expressing basket cells exhibit regular-spiking activity with accommodating action potentials (Pawelzik et al., 2002). Furthermore, after high-frequency trains of presynaptic spikes, GABA release of $\mathrm{CCK} / \mathrm{CB}_{1}$-positive basket cells is asynchronous with the presynaptic action potentials: latencies of postsynaptic responses are greatly variable, while PV-containing basket cells show highly synchronous release (Hefft and Jonas, 2005). In contrast to PV-positive basket cells that generates IPSCs in their postsynaptic pyramidal cells reliably with consistent amplitude, CCK/CB 1 -positive basket cells show large fluctuations of the postsynaptic response, and failures of synaptic transmission are more frequent (Hefft and Jonas, 2005; Daw et al., 2009; Szabó et al., 2010). In addition, $\mathrm{CCK} / \mathrm{CB}_{1}$-positive basket cells have two nonoverlapping subgroups: one of them contain vasoactive intestinal polypeptide (VIP) (Acsády et al., 1996), whereas the other subgroup expresses vesicular glutamate transporter 3 (vGluT3) (Somogyi et al., 2004). Several other differences of their molecular composition, intrinsic features, input and output properties have already been described in detail (Glickfeld and
Scanziani, 2006; Armstrong and Soltesz, 2012; Bartos and Elgueta, 2012). Briefly, in functional terms, while PV-positive basket cells are ideally suited for generating fast network oscillations, $\mathrm{CCK} / \mathrm{CB}_{1}$-expressing basket cells rather provide a tonic form of inhibition and act as a „fine-tuning device” in the hippocampus (Freund and Katona, 2007).

The third type of perisomatic interneuron is the axo-axonic cell, which is also PV-positive (Katsumaru et al., 1988) and releases GABA with precise timing and low failure rates similarly to PV-containing basket cells (Maccaferri et al., 2000; Szabó et al., 2010). While it is clear that basket cells inhibit their target neurons, the effect of axo-axonic cells is still debated and it can be either excitatory (Szabadics et al., 2006) or inhibitory (Glickfeld et al., 2009). In addition, the three perisomatic interneuron groups are active at different times and show different firing patterns during network oscillations in vivo (Klausberger et al., 2003; Klausberger et al., 2005; Tukker et al., 2007; Lasztóczi et al., 2011; Lapray et al., 2012; Tukker et al., 2013) and also in in vitro preparations (Gulyás et al., 2010; Hájos et al., 2013).

In this study, we estimated how many PV- or $\mathrm{CB}_{1}$-expressing boutons innervate one pyramidal cell soma in CA1 and CA3, and tested whether other inputs may also innervate the somatic membrane. We also determined that the majority of the $\mathrm{CB}_{1}$-positive somatic boutons express vGluT3. It was shown in several studies that morphological parameters of synaptic boutons (size and shape of boutons; number of postsynaptic targets; number, arrangement and size of active zones; number and size of mitochondria; presence of dense core vesicles etc.) can correlate well with their physiological properties (Kubota and Kawaguchi, 2000; Telgkamp et al., 2004; Rollenhagen and Lübke, 2006; Bodor et al., 2008; Yoshida et al., 2011; Holderith et al., 2012). After 3-dimensional reconstruction of perisomatic boutons, we measured these parameters to allow a comparison to their different functional properties and found that differences among interneuron types are manifested even in the finest ultrastructural details of their terminals possibly reflecting the adjustment of the signalling and vesicular release machinery to the requirements of the activity pattern.

\section{Materials and Methods}

\section{Animals}

All experiments have been approved by the Animal Care and Experimentation Committee of the Institute of Experimental Medicine of Hungarian Academy of Sciences and the Animal Health and Food Control Station, Budapest and performed in accordance with the 
ethical standards laid down in the 1964 Declaration of Helsinki and its later amendments.

Twelve 24-60 days old male C57BL/6J mice were sacrificed. For perfusion, mice were anaesthetized with isoflurane followed by an intraperitoneal injection of an anesthetic mixture (containing 0.83\% ketamine, $0.17 \%$ xylazin hydrochloride, $0.083 \%$ promethazinium chloride, $0.00083 \%$ benzethonium chloride, and $0.00067 \%$ hydrochinonum) to achieve deep anesthesia. In this study, we performed three different immunohistochemical experiments that required different fixation method and tissue processing (see below).

\section{Double fluorescent labeling and confocal microscopy}

Six mice between the age of 24 and 60 days were perfused transcardially under deep anesthesia first with $0.9 \% \mathrm{NaCl}$ solution for $2 \mathrm{~min}$ followed by $4 \%$ paraformaldehyde for $40 \mathrm{~min}$ and finally with $0.1 \mathrm{M}$ phosphate buffer (PB) for $10 \mathrm{~min}$. The brains were removed from the skull and coronal sections were cut on a Leica VT1200S vibratome at $60 \mu \mathrm{m}$. After washing out fixative with $0.1 \mathrm{M} P B$ for $1 \mathrm{~h}$, sections were cryoprotected sequentially in 10\% (30 min) and 30\% (overnight) sucrose in PB and freeze-thawed four times over liquid nitrogen. Then sections were washed in $\mathrm{PB}$ and Tris buffered saline (TBS), and blocked with 1\% human serum albumin in TBS (Sigma-Aldrich Inc.) for 1 h. The sections were incubated in the primary antibody solution for 3 days, containing goat anti-CB C $_{1}$ receptor (1:500, gift from Prof. Masahiko Watanabe) and rabbit anti-vGluT3 (1:500, Synaptic Systems, Cat. No. 135 203) in TBS. After subsequent washes in TBS, sections were incubated in secondary antibodies for $4 \mathrm{~h}$, containing Alexa Fluor 594 donkey-anti-goat (1:200500) and Alexa Fluor 488 donkey-anti-rabbit (1:200500 ) in TBS. This was followed by washing in TBS and $\mathrm{PB}$, and then the sections were transferred to and dried on slides, and covered with Aquamount (BDH Chemicals Ltd.). The sections were analyzed using an Olympus Optical FluoView 300 confocal laser scanning microscope in sequential scanning mode, using 60-times magnifications. Image stacks were taken randomly from different scanning sites in the pyramidal cell layer of the CA1 region of six mice and in the CA3 region of three mice.

\section{Double labeling immunoelectron microscopy}

Three mice (36 days old) were perfused transcardially under deep anesthesia with $0.9 \% \mathrm{NaCl}$ for 2 min followed by a fixative containing $4 \%$ paraformaldehyde, $0.1 \%$ glutaraldehyde, and $15 \%$ (v/v) saturated aqueous solution of picric acid in PB for $30 \mathrm{~min}$. The brains were removed from the skull and postfixed in the same fixative without glutaraldehyde for $1 \mathrm{~h}$ at room temperature. Then, we cut and washed the sections, cryoprotected, freeze-thawed and washed them again, as described above. Endogenous peroxidase-like activity was blocked by 1\% hydrogen peroxide in TBS for 15 min. After several rinses in TBS, sections were blocked in $10 \%(\mathrm{v} / \mathrm{v})$ normal goat serum (in TBS; Vector Laboratories) for $45 \mathrm{~min}$ and then incubated in rabbit anti-CB $\mathrm{CB}_{1}$ primary antibody solution (1:5000 in TBS; gift from Prof. Ken Mackie) for 2 days at 4C. After extensive washes, sections were treated with biotinylated goat antirabbit IgG (1:600; Vector Laboratories) for $4 \mathrm{~h}$ at room temperature, followed by repeated washes in TBS and an overnight incubation in avidin-biotinylated horseradish peroxidase complex (1:500 in TBS; Elite ABC, Vector Laboratories) at $4 \mathrm{C}$. $\mathrm{CB}_{1}$-labeling was visualized by an immunperoxidase reaction developed by 3, 3'diaminobenzidine with ammonium nickel sulphate (DABNi) and then post-intensified with silver-gold (Dobó et al., 2011). This intensification step converts the labeling from homogenous to granular by loading fine gold particles onto the DABNi deposit. After washes in TBS, sections were treated with $1 \%$ hydrogen peroxide in TBS for $15 \mathrm{~min}$ to avoid the possibility that peroxidase activity of bounded $\mathrm{ABC}$ has any effect on the second labeling. Sections then were blocked in $10 \%$ (v/v) normal horse serum (Vector Laboratories) for 45 min and incubated in a mouse monoclonal anti-PV primary antibody solution (1:8000 in TBS; Swant, Bellinzona, Switzerland) for 2 days at 4C. This step was followed by incubation with anti-mouse ImmPRESS (1:4 in TBS; Vector Laboratories) overnight at 4C. The second immunperoxidase reaction was developed by DABNi, resulting in a homogenous deposit, which was clearly distinguishable from the silver-gold intensified DABNi at the electron microscopic level (Dobó et al., 2011).

\section{Preembedding immunogold staining}

Three mice between the age of 35 and 41 days were perfused transcardially under deep anesthesia first with $0.9 \% \mathrm{NaCl}$ for 2 min followed by a fixative containing $2 \%$ paraformaldehyde and $1 \%$ glutaraldehyde in $0.1 \mathrm{M}$ sodium acetate buffer ( $\mathrm{pH}$ 6.5) for $2 \mathrm{~min}$, and then by $2 \%$ paraformaldehyde/1\% glutaraldehyde in $0.1 \mathrm{M}$ sodium borate buffer (pH 8.5) for $1 \mathrm{~h}$ (Berod et al., 1981). Brains were kept in the skull overnight at $4^{\circ} \mathrm{C}$. Then, we cut and washed the sections, cryoprotected, freeze-thawed and washed them again, as described above. Sections were treated with $0.5 \%$ sodium borohydride in PB for 15 min and were then washed again in PB and TBS. Sections were blocked in $10 \%(\mathrm{v} / \mathrm{v})$ normal goat serum (Vector Laboratories) for $1 \mathrm{~h}$ followed by incubation in rabbit anti-CB 1 (1:1000; gift from Prof. Ken Mackie) or rabbit 
anti-PV (1:2000; gift from Prof. Kenneth G. Baimbridge) primary antibody solutions diluted in TBS for 2 days at 4C. After extensive washes in TBS, sections were blocked for 30 min with $0.8 \%$ bovine serum albumin and $0.1 \%$ cold water fish skin gelatin in TBS containing $0.05 \%$ sodium azide and then incubated in $0.8 \mathrm{~nm}$ goldcoupled goat anti- rabbit IgG (1:50; Aurion) diluted in blocking solution overnight at $4^{\circ} \mathrm{C}$. After washes in TBS, sections were treated with $2 \%$ glutaraldehyde in TBS for $10 \mathrm{~min}$ to fix the gold particles into the tissue. Gold particles were intensified using the Aurion Silver Enhancement Solution (SE-EM; Aurion) as described by the manufacturer.

\section{Specificity of antibodies}

The specificity of the rabbit anti-vGluT3 (Synaptic

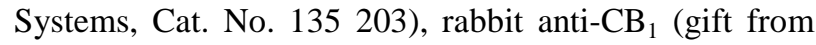
Dr. Ken Mackie) and goat anti-CB ${ }_{1}$ (gift from Dr. Masahiko Watanabe) antibodies were tested several times in different laboratories (e.g.: rabbit anti-vGluT3: Seal et al., 2008; rabbit anti-CB $\mathrm{CB}_{1}$ : Bodor et al, 2005; goat anti-CB : $_{1}$ Uchigashima et al., 2007) and they were proved to be specific. In addition, we also tested these antibodies several times in knock-out mice in our immunohistochemistry experiments and they were proved to be specific. Furthermore, the localization of these molecules in hippocampus is well known, therefore the staining pattern provided by these antibodies in our experiments confirmed their specificity as well. The specificity of rabbit anti-PV antibody (Code No. R301, gift from Dr. Kenneth G. Baimbridge) was tested and characterized extensively (Mithani et al., 1987; Sloviter, 1989) and we also found the expected labeling pattern in hippocampus. The mouse monoclonal anti-PV antibody (Swant, Bellinzona, Switzerland) that gives similar labeling pattern as the rabbit anti-PV antibody was tested by the manufacturer and it did not stain the brain of PV knock- out mice. Secondary antibodies were also extensively tested for possible cross-reactivity with the other secondary or primary antibodies, and possible tissue labeling without primary antibodies was also tested to exclude autofluorescence or specific background labeling by the secondary antibodies. No specific-like staining was observed under these control conditions.

\section{Tissue processing for electron microscopy}

Sections used for electron microscopy were treated with 0.5\% osmium tetroxide (in $\mathrm{PB} ; 20 \mathrm{~min}$ on ice), dehydrated in an ascending ethanol series followed by acetonitrile and embedded in Durcupan (ACM, Fluka). During dehydration, sections were treated with $1 \%$ uranyl acetate in 70\% ethanol for 20 min. For electronmicroscopic analysis, tissue samples from the middle portion of the rostro-caudal axis of the dorsal hippocampus were glued onto small Durcupan blocks. Long series of consecutive ultrathin sections (at least 100 sections/ series, 40 or $60 \mathrm{~nm}$ thick) were cut using an ultramicrotome (Leica EM UC6) and picked up on Formvar-coated single-slot grids. Ultrathin sections were counterstained with lead citrate (Ultrostain 2, Leica) and examined in a Hitachi 7100 electron microscope equipped with a Veleta CCD camera (Olympus Soft Imaging Solutions, Germany).

\section{Electron microscopic reconstruction of pyramidal cell somata and its synaptic terminals}

The densities and numbers of $\mathrm{PV}$ or $\mathrm{CB}_{1}$-positive somatic terminals on pyramidal cells and the total surface area of a pyramidal cell soma were determined using consecutive serial electron microscopic sections double labeled for PV and $\mathrm{CB}_{1}$ [see above, (Dobó et al., 2011)]. For calculation of the total surface area of a pyramidal cell soma, pyramidal cell bodies were traced and photographed in every fifth 60-nm-thick electron microscopic section of a series, where they were present $(\mathrm{n}=9$ and 3 somata from CA1 and CA3, respectively). From these images (about 38 and 90 images per soma, median in CA1 and CA3 respectively), somata were completely reconstructed and their surfaces were measured using the Reconstruct software (Fiala, 2005). Since there is no physically identifiable border between somatic and dendritic membranes, somatic membranes were identified as membranes of image profiles, where the smallest diameter of the profile was larger than 4.5 $\mu \mathrm{m}$.

For measurements of bouton density, pyramidal cell somata were selected from the surface of the $60 \mu \mathrm{m}$ thick block, where the penetration of immunoreagents was perfect ( $\mathrm{n}=11$ and 10 somata from CA1 and CA3, respectively). Only somata that had a large crosssectional area on the given section were selected to reduce the number of boutons with tangentially sectioned synapses. Membrane of each selected soma was traced in serial 60 -nm-thick sections ( $\mathrm{n}=40-63$ sections) and was reconstructed together with synaptic terminals. Individual $\mathrm{PV}$ - or $\mathrm{CB}_{1}$-positive or double-negative synaptic boutons were followed and their position was labeled on the drawings. Boutons being in contact with the soma and present in the reference section series were counted, except those present also in the look-up-section (the section preceding the first reference section). The vast majority of the juxtaposed/contacting boutons established synapses with the soma, but occasionally the synaptic cleft was not clearly visible, most probably because it was sectioned too tangentially. Nevertheless, all boutons in contact with the pyramidal cell somata were counted as synaptic terminals, because of the 
following reasons. In this study, we fully reconstructed 131 immunogold-labeled somatic boutons (see below), all of them with at least one somatic synapse. Thirty of them made two appositions/contacts with pyramidal somata, out of which only three of them $(10 \%)$ had a contact, but did not have a synapse with both pyramidal cell bodies. However even latter these boutons formed synapses with one of the pyramidal cell somata. These suggest that the probability that a bouton does not form a synapse with a soma is far less than $10 \%$. The vast majority of the juxtaposed/contacting boutons formed visible synapse with the soma. Those few boutons that were in contact with the soma, but had no clearly visible synaptic cleft were also counted in these measurements, because there was an at least a $90 \%$ probability that they also form a synapse. Photos were taken in every fifth sections for measurements of the sampled soma surfaces. For calculation, perimeters of soma membrane crosssections were measured using the Fiji/ImageJ program and multiplied by the number of sections $(n=5)$ between two photographs and the section thickness $(60 \mathrm{~nm})$.

The total somatic surfaces were different among animals probably due to shrinkage differences; therefore, results from the three mice were analyzed separately. To calculate the bouton density, the total number of boutons collected in one animal was divided by the total surface area tested in the same animal, while stereological rules were also observed (see above). To estimate the total number of boutons on CA1 and CA3 pyramidal cell somata, these density values (number of inputs/ $\mu \mathrm{m}^{2}$ ) were multiplied by the estimated whole surface area of pyramidal somata measured in the same animal. We have measured somatic surfaces in all 3 mice from CA1, while due to the extremely laborious nature of these measurements (in CA3, about 600 continuous sections was needed per animal) pyramidal cell surface area in the CA3 region was estimated from only one mouse, while measurement was corrected with shrinkage data calculated based on fully reconstructed nuclei.

\section{Electron microscopic reconstruction of perisomatic boutons}

Pyramidal cell layer was systemically scanned for immunogold-labeled boutons forming synapses with pyramidal somata. These boutons were followed in consecutive serial sections and digital images were taken at 30,000 times magnification in each serial section. Other immunogold-labeled boutons that established synapses in these series were also included in the sample, while terminals having not clearly visible synapses were excluded. Three-dimensional reconstructions of membranes, synaptic membranes and mitochondria of boutons ( $n=160)$ were made using the Reconstruct software (Fiala, 2005). Profiles in each image within a stack were traced to create a three-dimensional object. Volume and surface area of the traced objects were then measured using the Reconstruct software. Measurements did not include intervaricose axon segments, therefore the 3-dimensionally reconstructed boutons were truncated at the point, where the axonal profiles abruptly became only a very small axonal fiber. All boutons in the $\mathrm{CB}_{1}$-positive category $(\mathrm{n}=59)$ and most of the boutons in the PV-positive group (92\%, 66/72) were reconstructed from sections immunostained for $\mathrm{CB}_{1}$ and $\mathrm{PV}$, respectively. Six $\mathrm{CB}_{1}$-negative perisomatic bouton in CA1 area were reconstructed from sections immunostained for only $\mathrm{CB}_{1}$ and these boutons were considered PV-positive, because of the extremely low occurrence of double-negative somatic boutons in sections double stained for $\mathrm{PV}$ and $\mathrm{CB}_{1}(1.5 \%$ of all somatic boutons, see Results). All but two $\mathrm{CB}_{1}$-positive boutons and $50 \%$ of PV-positive boutons were reconstructed from $40 \mathrm{~nm}$-thick sections, whereas the rest of the terminals were reconstructed from $60 \mathrm{~nm}$ thick sections ( $n=21-6140$ nm-thick sections/bouton; $n=19-5560$ nm-thick sections/bouton). For the reconstruction of $\mathrm{CB}_{1}$-positive boutons thinner (40 nmthick) sections were more advantageous, because of the more complex shape of synapses compared to those of the PV-positive boutons (see Results). Axo-axonic boutons were recognized by the characteristics of their postsynaptic target: the axon initial segment (AIS). AIS has an electron-dense membrane undercoating, characteristic bundles of microtubules and stacked endoplasmic cisterns [Fig. 5A, (Palay et al., 1968; ChanPalay, 1972; Somogyi, 1977)]. Axo-axonic boutons were reconstructed from sections immunostained for $\mathrm{PV}$ or $\mathrm{CB}_{1}$ (they were $\mathrm{PV}$-positive and $\mathrm{CB}_{1}$-negative) using either 40 ( $n=21$ boutons; $n=20-49$ sections/bouton) or 60 nm-thick ( $\mathrm{n}=8$ boutons; $\mathrm{n}=16-39$ sections/bouton) sections. Measured morphological parameters from 40 and $60 \mathrm{~nm}$ thick sections were statistically not different; therefore, as expected, comparisons were not influenced by section thickness.

\section{Statistical analysis}

All statistical analyses were carried out using the software package Statistica (StatSoft, Tulsa, OK, USA). We used non-parametric statistics for comparison of populations. Medians and interquartile ranges were used to describe distributions. Two groups were compared using the Mann-Whitney $U$ test. The differences were considered significant at $\mathrm{p}<0.05$, but higher level of significance at $\mathrm{p}<0.01$ is also reported. Significance levels where established using Bonferroni's correction for preventing over-testing due to multiple comparison. 


\section{Results}

\section{Convergence of $\mathrm{PV}$ - and $\mathrm{CB}_{1}$-positive somatic inputs} onto pyramidal somata

As described in the Methods section, PV-positive profiles were labeled by homogenous DABNi deposit, whereas $\mathrm{CB}_{1}$-positive elements were labeled by goldintensified-DABNi, which is studded with fine metal particles (Fig. 1, compare $\mathrm{B}_{1-2}$ with $\mathrm{C}$ ). Pyramidal somata were traced in consecutive serial electron microscopic sections and bouton density was determined by dividing the number of synaptic boutons ( $\mathrm{n}=191$ and 238 from CA1 and CA3, respectively) of a given membrane area with the surface of the examined part of the membrane (976 $\mu^{2}$ collected from 3 mice, from 11 cells in CA1and $1113 \mu \mathrm{m}^{2}$ collected from 3 mice, from 10 cells in CA3, see Methods, for details see Table 1, row 2-5 and row 15-18), observing stereological principles. These data revealed the density of PV-positive and $\mathrm{CB}_{1}$ positive somatic boutons innervating $100 \mu^{2}$ somasurface in the CA1 and CA3 area, and revealed that in CA1 and CA3 about $60 \%$ of the somatic terminals are PV-positive, while about $35-40 \%$ is $\mathrm{CB}_{1}$-positive (See Table 1).

The typical full surface area of CA1 and CA3 pyramidal somata was also sampled (see Methods for details of measurements). For data, see Table 1. To calculate the total number of somatic inputs, we used the median value of the somatic full surface areas and we multiplied it with the density of somatic boutons in the same animal. According to our calculation, an average CA1 pyramidal soma was innervated by about 60 boutons, about 40 of which are PV-positive and about 20 are CB1-positive. Furthermore, a typical CA3 pyramidal cell soma (the surface of which is about 2.3-times larger than in CA1) would be innervated by about 140 boutons, about 90 of which are PV-positive and about 50 are $\mathrm{CB}_{1}$ positive. Some double negative boutons could also be observed. All data are presented in Table 1.

Some properties of CA1 pyramidal cells depend on the vertical soma-position inside the layer (Slomianka et al., 2011), and, although we did not plan to test such differences, our samples were taken from different sublayers to have a better representation, and we did not notice any differences in perisomatic innervation.

\section{Most of the CB1-positive terminals are vGluT3- positive in the mouse hippocampus}

As described above, $\mathrm{CCK} / \mathrm{CB}_{1}$-positive basket cells have two non-overlapping subgroups: one expresses vGluT3, whereas the other is vGluT3 negative, but contains VIP. Although we know the proportions of their somata in rat hippocampus (Somogyi et al., 2004), it does not necessarily reflect the proportions of their terminals around pyramidal cells. Here, we performed double immunofluorescent stainings for $\mathrm{CB}_{1}$ and vGluT3 and tested how many of the terminals are of the vGluT3 positive subtype (Fig. 2). In immunofluorescent measurements, we tested terminals in the pyramidal cell layer; however, it is impossible to select only terminals that target somata, therefore, some of the vGluT3 positive terminals (about $7 \%$ in CA1 and about $10 \%$ in CA3) were $\mathrm{CB}_{1}$-negative. On the other hand, we found that the vast majority of $\mathrm{CB}_{1}$-containing terminals (about $85 \%$ of $\mathrm{CB}_{1}$ in $\mathrm{CA} 1$ and about $94 \%$ of $\mathrm{CB}_{1}$ in $\mathrm{CA} 3$ ) were vGluT3 positive. All data are presented in Table 2.

\section{PV-positive and $\mathrm{CB}_{1}$-positive somatic boutons have characteristically different shapes}

To describe the ultrastructural properties of these somatic boutons, first we identified them using either PV- or $\mathrm{CB}_{1}$-labeling in sections with optimal ultrastructural preservation (see Methods). Because electron dense precipitate of DAB obscures fine ultrastructural details of labeled profiles, we visualized the two markers with silver-enhanced preembedding immunogold labeling. In sections immunostained for PV, scattered metal particles were present in the cytoplasm of a group of somatic boutons and in axo-axonic terminals (Figs. 3 A-E, 5 AC). Metal particles labeling $\mathrm{CB}_{1}$ receptors were attached to the membranes of a population of perisomatic boutons as shown earlier (Figs. $4 \mathrm{~A}_{1-7}$ and $\mathrm{E}$ ) (Katona et al., 1999).

For comparison of morphological properties of different basket cell terminals, we reconstructed $39 \mathrm{PV}$ positive somatic boutons (including $6 \mathrm{CB}_{1}$-negative boutons, for details see: Electron microscopic reconstruction of perisomatic boutons in the Methods section) and $33 \mathrm{CB}_{1}$-positive somatic boutons from CA1, and 33 PV-positive and $28 \mathrm{CB}_{1}$-positive somatic boutons from CA3 (from 3 mice, Fig. 3 and 4). Data from the 3 mice were not statistically different, therefore they were pooled (Table 3).

The variability of the volumes were similar in the two populations of somatic boutons and there were no significant differences between the volume of boutons reconstructed from CA1 and CA3 (Figs. 7A, 9; Table 3). We noticed, however, that the shapes of the PV- and $\mathrm{CB}_{1}$-positive boutons were characteristically different: most of the $\mathrm{CB}_{1}$-positive boutons were flat compared to PV-positive boutons, which were more spherical (Figs. $3,4,6)$. Objects with flat shapes possess larger surface area relative to their volume compared to more spherical objects. Indeed, the surface/ volume ratio was significantly lower for PV-positive boutons than for $\mathrm{CB}_{1}$ positive terminals (Figs. 7, 9; Table 3). These data mean that $\mathrm{CB}_{1}$-positive boutons had larger membrane surfaces 
in apposition to pyramidal cells than PV-positive somatic boutons (Figs. 1, 3, 4, and 9; Table 3).

\section{Mithochondria occupy larger volume in PV-positive boutons than in $\mathbf{C B}_{1}$-positive terminals}

Almost all of the reconstructed somatic boutons contained mitochondria with the exception of three $\mathrm{CB}_{1}$ positive terminals in $\mathrm{CA} 3$ (which was $11 \%$ of the $\mathrm{CB}_{1}$ positive boutons in CA3). PV-positive boutons had one, two, three or four mitochondria, the incidences of which were $50 \%, 37 \%, 11 \%$ and $3 \%$ in CA1 and $45 \%, 45 \%$, $6 \%$ and $3 \%$ in $\mathrm{CA} 3$, respectively. $\mathrm{CB}_{1}$-positive boutons had one, two, three, four or five mitochondria, the incidences of which were $48 \%, 36 \%, 6 \%, 9 \%$ and $0 \%$ in CA1 and $46 \%, 32 \%, 7 \%, 0 \%$ and $4 \%$ in CA3, respectively.

Most of the mitochondria had sausage- or kidney-bean shape (Fig. 6), but some of them showed more complex shapes. Volumes of individual mitochondria were significantly larger in PV-positive boutons than in $\mathrm{CB}_{1}$-positive ones both in CA1 and CA3 areas (Fig. 9, Table 3). The volume occupied by all mitochondria was also significantly larger for PVpositive boutons (Fig. 9, Table 3). One of the most distinguishable difference between the two types of terminals was the larger percentages of volume occupied by mitochondria in PV-positive boutons (median, 27\% in CA1 and 30\% in CA3) than in $\mathrm{CB}_{1}$-positive terminals (median, 16\% in CA1 and 21\% in CA3) (Table 3; Figs. 6 and 9). As shown in Fig. $8 \mathrm{~A}_{1-2}$ the total mitochondria volume showed a strong correlation with the volume of the boutons. Statistical data are presented in Figs. 7, 8, 9 and Table 3.

Different synaptic structure of $\mathrm{PV}$-positive and $\mathrm{CB}_{1^{-}}$ positive somatic boutons

Synaptic active zones were identified by the following criteria: i, a rigid mostly parallel apposition of the preand postsynaptic membranes; ii, wider and denser extracellular space in the presumed synaptic cleft; iii, pre- and postsynaptic membranes are more electrondense than extrasynaptic membranes; iv, accumulation of vesicles adjacent to a large portion of the presynaptic membrane, latter of which is not necessarily visible on all sections of the synapse.

Most of the reconstructed $\mathrm{PV}$ and $\mathrm{CB}_{1}$-positive somatic boutons formed more than one type 2 (symmetrical) synapses; however, their synaptic structures were remarkably different. Synapses of PVpositive boutons, defined by these criteria, were small and had a round or oval shape (Figs. 3 and 6) and synaptic vesicles were abundant adjacent to the synaptic active zones (Fig. 3A-E). Synapses of PV-positive boutons were clearly separated from non-synaptic membranes and their boundaries were unequivocally identifiable. Distinct synapses of the same PV-positive bouton were usually separated from each other by a relatively large non-synaptic membrane area (Fig. 3F-H). Many times a single punctum adherens was present at the edge of synapses or at other parts of the non-synaptic membranes. Puncta adherentia were distinct from synapses, because they were present in only one or two 60 nm-thick sections and have thick pre- and postsynaptic membrane specialization without associated vesicles (Lieberman and Spacek, 1997; Bodor et al., 2008).

Synapses of $\mathrm{CB}_{1}$-positive boutons frequently had an irregular shape (Figs. 4B, 6), which was not observed in synapses of PV-positive boutons. Synaptic membrane domains of $\mathrm{CB}_{1}$-positive boutons innervating the same target were frequently very close to each other (Figs. 4, 6), and appeared to share the same vesicle pool. In these cases, it cannot be determined whether these synaptic membrane segments are parts of a large irregular-shaped synapse or they are distinct individual synapses; therefore, we did not attempt to define the size of individual synapses for $\mathrm{CB}_{1}$-positive boutons. Vesicle clusters were less dense at synapses of $\mathrm{CB}_{1}$-positive boutons than in PV-positive terminals (Figs. 3A-E, 4A $\mathrm{A}_{1-7}$ and $\mathrm{E}$ ). We have also detected puncta adherentia between $\mathrm{CB}_{1}$-positive boutons and somata (or dendrites).

\section{Somatic boutons can target more than one postsynaptic element}

In addition to the innervated pyramidal soma, many of the reconstructed boutons, especially in the CA1 area, targeted one or two other postsynaptic profiles, which could be other somata or adjacent dendritic elements. Occasionally, PV-positive somatic boutons in the CA3 area established type 2 synapses with somatic spines (three out of 33 boutons) as well. These spines were different from typical dendritic spines of pyramidal cells because they did not have an asymmetric input. In the analysis below, synapses established with these spines were included into the somatic synapse category. Spines on somata of pyramidal cells were not observed in the CA1 area.

In the CA1 area, where pyramidal somata seemed to be more densely packed than in the CA3 area, the incidence of boutons targeting more postsynaptic profiles was higher. In general, PV-positive boutons diverged to two targets (or even to three in CA1), which was more frequent than in case of $\mathrm{CB}_{1}$-positive boutons in both examined areas.

In the CA1 area, 54\% $(n=21)$ of the PV-positive boutons $(n=39)$ formed synapses with two targets and $18 \%(n=7)$ of them with three postsynaptic targets (Fig. $3)$, whereas only $33 \%(n=11)$ of $\mathrm{CB}_{1}$-positive terminals 
$(n=33)$ innervated two targets (Figs. 4A and E), and 9\% of them $(n=3)$ had three targets. The incidence of two somatic targets was $33 \%(n=13)$ in case of PV-positive boutons and $18 \%(n=6)$ in case of $\mathrm{CB}_{1}$-positive terminals, while the rest targeted one soma and one or two passing dendrites in CA1.

In the CA3 area, $45 \%(n=15)$ of the PV-positive boutons $(\mathrm{n}=33)$ formed synapses with two targets and none of them with three postsynaptic targets, whereas only $7 \% \quad(n=2)$ of $\mathrm{CB}_{1}$-positive terminals $(\mathrm{n}=28)$ innervated two targets and none of them had three targets. The incidence of two somatic targets was $27 \%$ $(n=9)$ in case of PV-positive boutons, while the rest targeted one soma and a passing dendrite in CA3. None of the $\mathrm{CB}_{1}$-positive boutons had two somatic targets in CA3.

\section{Number of synapses per individual boutons}

As described above, somatic boutons target more than one postsynaptic element, but these elements are frequently targeted by more than one synapse of the same bouton. Only a minority of PV-positive somatic boutons formed only one synapse (10\% in CA1, 15\% in CA3), the rest established more than one synapse ( $90 \%$ in CA1 and $85 \%$ in CA3). These synapses might terminate on only one soma or two somata or on an adjacent dendrite as well (see above, Fig. 3). Two, three, four, and five synapses were established by $46 \%$, 26\%, $10 \%$ and $8 \%$ of the PV-positive boutons in CA1 and $36 \%, 39 \%, 6 \%$ and $3 \%$ of the boutons in CA3, respectively.

The same soma mostly receives only one or two synapses from a PV-positive bouton. Quantitatively, a bouton established one, two, three or four synapses on a given soma, the incidences of which were $54 \%, 42 \%, 2 \%$ and $2 \%$ in CA1 and $48 \%, 30 \%, 18 \%$ and $5 \%$ in CA3 (Figs. 3D and E).

As described above, individual synapses of $\mathrm{CB}_{1}$-positive boutons were usually not clearly separated from each other, and therefore we could not determine their total number. However, it was evident, that these boutons may also form more synapses with their postsynaptic somata (Figs. 4 and 6), as shown earlier in rat (Biró et al., 2006).

\section{$\mathrm{CB}_{1}$-positive somatic boutons form larger synapses than PV-positive boutons}

The total synaptic surface (area of all synapses of a bouton, including synapses with all postsynaptic targets) of $\mathrm{CB}_{1}$-positive boutons was significantly larger than that of PV-positive boutons, both in CA1 and CA3 (Figs. 6-9, Table 3). The variability of the total synaptic area of $\mathrm{CB}_{1}$-positive boutons was much larger than that of PVpositive boutons (Fig. 7D, Table 3). The size of the total synaptic areas showed a positive correlation with the volume of the boutons as shown in Fig. $8 \mathrm{~B}_{1-2}$.

Putative individual synapses of $\mathrm{CB}_{1}$-positive terminals established on the same postsynaptic element were so close to each other that we could not objectively separate them (see above). However, if we considered them separate active zones, these were probably also larger than those of PV-positive boutons (compare synapses shown in Figs. 3 and 4, Fig. 6). Statistical data are presented in Figs. 7, 8, 9 and Table 3.

Based on the abovementioned data in Table 1 and 3 , the synaptic coverage of pyramidal cell somata can also be calculated. Synaptic coverage can be calculated by multiplying the number of input-boutons per pyramidal cell soma (Table 1, row 10-12 and 23-25) with the average synaptic area of that type of bouton (Table 3, medians in row 8), divided by the somatic surface area of the pyramidal cell (Table 1, row 9 and 22 ). The median proportion of somatic surface occupied by PV-positive synapses was $0.86 \%$ on CA1 pyramidal cells $(n=9)$ and $0.75 \%$ on CA3 pyramidal cells $(n=3)$, whereas for $\mathrm{CB}_{1}$-positive synapses it was $1.57 \%$ on $\mathrm{CA} 1$ pyramidal cells $(n=9)$ and $1.46 \%$ on CA3 pyramidal cells $(n=3)$. The total synaptic coverage is $2.43 \%$ in CA1 and $2.21 \%$ in CA3. This is larger than that found by Kasugai et al. in rat using replica samples $(0.72 \%$ in CA1) (Kasugai et al., 2010).

\section{Different organization of intracellular organelles in the two types of perisomatic boutons}

Remarkably, dense core vesicles (DCV) were present in both types of boutons. In CA1, $64 \%$ of $\mathrm{CB}_{1}$ positive boutons $(n=33)$ had DCV $(52 \%$ of DCV containing boutons had $1 \mathrm{DCV}$, their median was 1 , one bouton had 17, another had $5 \mathrm{DCV}$, but the rest of DCV containing boutons had 3 or less DCV, Fig. 4E). In CA3, $82 \%$ of $\mathrm{CB}_{1}$-positive boutons $(n=28)$ had DCV (43\% of DCV containing boutons had $1 \mathrm{DCV}$, their median was 2, one bouton had $11 \mathrm{DCV}$, the rest of them had 6 or less DCV). In CA1, 31\% of PV-positive boutons ( $n=39)$ had DCV (67\% of DCV containing boutons had 1 DCV, their median was 1 , maximum was 3 DCV. In CA3, $27 \%$ of PV-positive boutons $(n=33)$ had DCV (67\% of DCV containing boutons had $1 \mathrm{DCV}$, their median was 1 , maximum was $3 \mathrm{DCV}$.

Although not analyzed quantitatively, it was apparent that the spatial arrangement of vesicles is different in the two types of boutons. In PV-positive boutons, the vesicle-cluster adjacent to synaptic membranes is denser (Fig. $3 \mathrm{~A}-\mathrm{E}$ ), whereas at synapses of $\mathrm{CB}_{1}$-positive terminals larger vesicle-free zones are also present along the synaptic membranes (Fig.4 $\mathrm{A}_{1-7}$ and $\mathrm{E}$ ). Inside the $\mathrm{CB}_{1}$-positve boutons larger areas are filled by vesicles compared to PV-positive boutons, 
probably because this space is usually occupied by larger mitochondria in PV-positive boutons. These vesicle pools are less densely packed than vesicles at the synaptic active zones.

Both populations of boutons frequently contained invaginations ( $46 \%$ and $42 \%$ of PV-positive boutons from CA1 and CA3, and $84 \%$ and $57 \%$ of $\mathrm{CB}_{1-}$ positive boutons from CA1 and CA3, respectively). Smaller invaginations typically originate from the innervated pyramidal cells, their soma membrane appears to protrude into the bouton (Figs. 3C and 4E). Our sample of reconstructed somatic terminals had no boutons with invaginations into somata ["invaginating boutons" (Yoshida et al., 2011)], but we sometimes observed similar $\mathrm{CB}_{1}$-positive boutons during the reconstruction of pyramidal soma membranes.

\section{Most of the ultrastructural properties of axo-axonic boutons are similar to those of PV-positive somatic boutons}

Axo-axonic boutons were reconstructed at the border of str. oriens and pyramidale ( $n=15$ in CA1, $n=14$ in CA3). They were recognized by the characteristics of their postsynaptic target: the axon initial segment (AIS), as described in the Methods. They were reconstructed from sections immunostained for $\mathrm{PV}$ or $\mathrm{CB}_{1}$ (they were PVpositive and $\mathrm{CB}_{1}$-negative).

The volume of axo-axonic boutons was smaller than that of somatic boutons (Figs. 5-9, Table 3). All but one axo-axonic bouton contained mitochondria. Most of these axo-axonic terminals had only one large mitochondrion (Figs. 5 and 6), with the exception of two terminals, which had two mitochondria and another bouton with four mitochondria. Like in PV-positive somatic boutons, the percentage of volume occupied by mitochondria inside the axo-axonic boutons was about 25\% in CA1 and 33\% in CA3 (Fig. 7C, Table 3). It was larger than in $\mathrm{CB}_{1}$-positive boutons, while it was similar to that in PV-positive boutons (Figs. 5-9, Table 3).

Most axo-axonic boutons ( $90 \%$ ) formed only one synapse with the AIS (Figs. 5 and 6 ) with the exception of three boutons. Two of them established two synapses with the same AIS. In these cases the two synaptic membranes were very close to each other, only a punctum adherens separated them. One axo-axonic bouton established another synapse with an adjacent dendrite. One of the reconstructed axo-axonic boutons from CA3 innervated a spine-like appendage of the AIS. Similar to synapses of PV-positive somatic boutons, synapses of axo-axonic boutons also had a macular shape and were accompanied by dense clusters of vesicles (Figs. 5 and 6).

Similar to somatic boutons, axo-axonic boutons also often contain dense-core vesicles (Fig. 5C). In CA1,
$53 \%$ of axo-axonic boutons $(n=15)$ had DCV (63\% of DCV containing boutons had $1 \mathrm{DCV}$, their median was 1, maximum was 2 DCV. In CA3, 50\% of axo-axonic boutons $(n=14)$ had DCV (57\% of DCV containing boutons had $1 \mathrm{DCV}$, their median was 1 , their maximum was 3 DCV). Axo-axonic boutons also had invaginations (47\% and $28 \%$ of boutons from CA1 and CA3, respectively), and have puncta adherentia, especially at the edge of synapses.

Correlation of bouton volume with the volume of mitochondria and the total synaptic area was tested as well, and these correlation lines almost overlapped with those of PV-positive boutons, but were different from those of $\mathrm{CB}_{1}$-positive terminals (see Fig. 8). Overall, our results showed that axo-axonic boutons were more similar to PV- positive somatic terminals than to $\mathrm{CB}_{1}$ positive somatic boutons. Statistical data are presented in Fig. 7, 8, 9 and Table 3.

\section{Discussion}

We found that hippocampal CA1 and CA3 pyramidal cells in mouse receive approximately 60 and 140 somatic inputs, respectively, $\sim 60 \%$ of which are PV-positive whereas $\sim 35-40 \%$ are $\mathrm{CB}_{1}$-positive. Boutons that are negative for both $\mathrm{PV}$ and $\mathrm{CB}_{1}$ make a weak contribution to the innervation of hippocampal pyramidal cell somata ( 1 and $4 \%$ of all somatic inputs in CA1 and CA3, respectively). The vast majority of $\mathrm{CB}_{1}$-positive perisomatic boutons contain vGluT3. The morphological parameters of persiomatic boutons are markedly different: PV-positive boutons are more spherical compared to $\mathrm{CB}_{1}$-positive terminals that are flat and have a significantly larger surface/volume ratio and larger surface membrane area facing the somatic membrane. Mitochondria of PV-positive somatic and axo-axonic boutons occupy a larger proportion of the bouton volume than in $\mathrm{CB}_{1}$-positive somatic boutons. Both types of somatic boutons frequently form multiple synapses with the same soma and also innervate other postsynaptic targets (adjacent dendrite(s) or another soma). While PVpositive basket terminals and PV-positive axo-axonic boutons have small macular synapses that are clearly separated from each other, synapses of $\mathrm{CB}_{1}$-positive boutons often have irregular shape and can be positioned very close to each other. The total synaptic areas of $\mathrm{CB}_{1^{-}}$ positive boutons are significantly larger than those of PV-positive boutons. Axo-axonic cell terminals are smaller than somatic boutons, have only one macular synapse and relatively large mitochondria. Interestingly, all the three types of perisomatic terminal populations contain dense-core vesicles. 
Convergence of different types of basket cells onto hippocampal pyramidal cell bodies

Our results indicate that more PV-positive boutons innervate the soma of hippocampal pyramidal cells than $\mathrm{CB}_{1}$-positive ones ( 37 PV-positive versus $\sim 23 \mathrm{CB}_{1}{ }^{-}$ positive somatic terminals in CA1 and $93 \mathrm{PV}$-positiveversus $\sim 50 \mathrm{CB}_{1}$-positive somatic terminals in CA3). In agreement with these data, earlier semi-quantitative analysis at the light microscopical level demonstrated that the number of PV-positive boutons per $100 \mu^{2}$ CA1 str. pyramidale is larger than that of $\mathrm{CB}_{1}$-positive terminals [13.1 \pm 0.4 and $10.6 \pm 0.2$, respectively; (Wyeth et al., 2010)]. However, in the present study, the ratio of $\mathrm{PV}$ versus $\mathrm{CB}_{1}$-positive boutons innervating CA1 pyramidal soma is $1.6: 1$ which is larger than that calculated from these earlier data (1.2:1). It may be explained by the fact that single PV-positive boutons can innervate more postsynaptic pyramidal somata more frequently than $\mathrm{CB}_{1}$-positive terminals do (in $\mathrm{CA} 1,33 \%$ versus $18 \%$ of the reconstructed $\mathrm{PV}$ - and $\mathrm{CB}_{1}$-positive boutons had two somatic targets, respectively).

Földy et al showed that in the CA1 region of the rat hippocampus individual PV-expressing and CCK/CB ${ }_{1}$-containing basket cells established $5.8 \pm 0.7$ and $2.3 \pm 0.8$ putative synaptic terminals with the somata of their postsynaptic pyramidal cells, respectively (Földy et al., 2010). If this convergence is similar in mouse, on average, 6.4 (37/5.8) PV-positive- and 10 (23/2.3) $\mathrm{CB}_{1^{-}}$ positive basket cells can converge onto an individual CA1 pyramidal soma. However, it should be noted that basket cells form large numbers of synapses with proximal dendrites as well (Halasy et al., 1996). PVpositive basket cells in rat usually establish similar numbers of synaptic terminals with proximal dendrites ( $\mathrm{n}=\sim 5.2 /$ pyramidal cell) and with a soma $(\mathrm{n}=\sim 5.8 /$ pyramidal cell), while $\mathrm{CCK} / \mathrm{CB}_{1}$-expressing basket cells in rat usually establish more synaptic terminals with proximal dendrites ( $\mathrm{n}=\sim 6 /$ pyramidal cell) than with a soma ( $\mathrm{n}=\sim 2.3 /$ pyramidal cell) (Földy et al., 2010). Using these data from rat, we can estimate that, in addition to their somatic inputs, the proximal dendritic region of CA1 pyramidal cells may also receive about 33 $(5.2 * 6.4)$ PV-positive and about $60(6 * 10) \mathrm{CB}_{1}$-positive boutons from basket cells, therefore, in total, about 70 (37+33) PV-positive and about $83(23+60) \mathrm{CB}_{1}$-positive basket cell terminals can converge onto individual CA1 pyramidal cells.

In rat, about $\sim 27 \%$ of the CCK-expressing interneuron somata are also positive for vGluT3, a nonoverlapping $\sim 11 \%$ of them are VIP-positive, $\sim 23 \%$ of them expresses calbindin and no VIP or vGluT3, whereas the rest of them $(\sim 39 \%)$ do not contain detectable vGluT3, VIP or calbindin (Kosaka et al., 1985; Somogyi et al., 2004). Therefore, the two subpopulations of CCK positive basket cells consist of about 71\% CCK/vGluT3 positive and about 29\% CCK/VIP positive basket cells in rat. We found that $\sim 85 \%$ and $\sim 95 \%$ of the $\mathrm{CB}_{1}$-positive somatic boutons contain vGluT3 in the CA1 and CA3 areas respectively, indicating either that in the mouse hippocampus there are more $\mathrm{CCK} / \mathrm{CB}_{1} / \mathrm{vGlut} 3$ positive basket cells relative to VIP containing ones, or CCK/CB $/$ /vGlut3-positive cells establish much more synapses than VIP positive cells, or there might be an unexpected overlap between vGlut3 and VIP positive basket cells in mouse. The contribution of these putative VIP positive boutons to the total somatic input might be less than 2-5\% (3 terminals out of 60 and 7 terminals out of 140 terminals in CA1 and CA3 pyramidal cell, respectively).

It was shown in several studies that in the hippocampus, not only basket cells, but occasionally other cell types also innervate pyramidal cell bodies (Ferraguti et al., 2005; Fuentealba et al., 2008; Takács et al., 2013). Here we show that the relative numerical contribution of these $\mathrm{PV}$ and $\mathrm{CB}_{1}$-negative inputs to the total innervation of pyramidal somata is very weak (1 and $4 \%$ of all boutons in CA1, and CA3, respectively).

\section{PV-positive terminals have relatively larger mitochondria.}

Volumes of individual mitochondria and the proportion of bouton volume occupied by these mitochondria were significantly larger in PV-positive terminals (i.e. PVpositive basket terminals and axo-axonic boutons) than in $\mathrm{CB}_{1}$-positive boutons. PV-positive basket and axoaxonic cells display fast spiking activity (Pawelzik et al., 2002) and probably are among the most active neurons in the cerebral cortex. In contrast to $\mathrm{CB}_{1}$-positive basket cells, firing of $\mathrm{PV}$-positive perisomatic interneurons show high temporal precision (Hefft and Jonas, 2005; Daw et al., 2009; Szabó et al., 2010), which requires fast recovery of energetic and ionic balance in the synaptic terminal after individual spikes. These mechanisms demand more intense ATP production, which may require these larger mitochondria. Immunostaining for cytochrome $\mathrm{C}$, an enzyme in mitochondria participating in the electron transport is also stronger in PV-positive interneurons than in CCK-positive cells, suggesting stronger metabolic rate for the PV-positive interneurons (Gulyás et al., 2006). Furthermore, the large size of mitochondria can be important in maintaining highfrequency transmission also because mitochondria participate in the sequestering of $\mathrm{Ca}^{2+}$ in the synaptic bouton (Billups and Forsythe, 2002). Interestingly, in several types of boutons, mitochondria were shown to be associated with the pool of synaptic vesicles (Rowland et al. 2000; Rollenhagen et al., 2007), however in our hippocampal perisomatic terminals, the space available 
for mitochondria and vesicles is so limited that they were inevitably close to each other, although mitochondria did not seem to be associated directly to the vesicles close to the synapses (see Figure 3-5).

\section{Synapses of $\mathrm{PV}$ and $\mathrm{CB}_{1}$-positive perisomatic cells are different.}

In this study, we found that $\mathrm{CB}_{1}$-positive somatic boutons formed irregular-shaped synapses, with variable synaptic area (similar to area of rat CCK-positive synapses (Biró et al., 2006)) on pyramidal cell somata, the total surface of which were much larger $\left(\sim 0.23 \mu \mathrm{m}^{2} /\right.$ individual soma) than synapses of PV-positive boutons ( $\sim 0.07 \mathrm{\mu m}^{2}$ / individual soma), the latter of which had small, macular synapses. Daw et al found that $\mathrm{CCK} / \mathrm{CB}_{1}{ }^{-}$ expressing basket cells produce postsynaptic responses with highly variable quantal amplitudes (including very large events) in their postsynaptic pyramidal cells compared to PV-positive basket cells that mediate quantal events with consistent amplitudes (Daw et al., 2009). The mIPSC amplitude depends predominantly on the number of postsynaptic receptors that are proportional to the size of the synapses (Nusser et al., 1997), therefore, higher variability of the size of different synapses of $\mathrm{CB}_{1}$-positive somatic boutons may provide an anatomical basis for their highly variable quantal events.

Several studies showed that synaptic connections between PV-positive basket cells and pyramidal cells are much more reliable than connections between $\mathrm{CCK} / \mathrm{CB}_{1}$-positive basket cells and pyramidal cells, in the latter of which connection failures of synaptic transmission are frequent (Hefft and Jonas, 2005; Daw et al., 2009; Szabó et al., 2010). These observations are not easily explained, because boutons with larger synaptic area are generally considered to be more efficient and faithful (Pierce and Lewin, 1994; Holderith et al., 2012). The probability of transmitter release depends on many factors, including the number of vesicles close to the synaptic active zones (Branco et al., 2010) and the distance between voltage-gated $\mathrm{Ca}^{2+}$ channels and synaptic vesicles at the release site (Meinrenken et al., 2003; Pang and Südhof, 2010), which harbor the $\mathrm{Ca}^{2+}$ sensor for exocytosis in their membrane (Jahn and Fasshauer, 2012). We noticed that the vesicle cluster close to the synaptic membrane was much denser in $\mathrm{PV}$-positive boutons than in $\mathrm{CB}_{1}$-positive terminals (compare Figs. $3 \mathrm{~A}-\mathrm{E}$ and $4 \mathrm{~A}_{1-7}, \mathrm{E}$ ); therefore larger pools of readily releasable vesicles can be present in the vicinity of active voltage-gated $\mathrm{Ca}^{2+}$ channels in these boutons, which certainly support a more reliable transmission. Due to the denser vesicle cluster at synaptic membranes, depletion of readily releasable vesicles can be more easily avoided in PV-positive boutons than in $\mathrm{CCK} / \mathrm{CB}_{1}$-positive terminals allowing high-frequency firing.

The two types of basket cells use different types of voltage-gated $\mathrm{Ca}^{2+}$ channels for transmitter release: $\mathrm{Ca}^{2+-}$ influx in PV-positive basket cell boutons is mediated by $\mathrm{P} / \mathrm{Q}$ type channels, whereas $\mathrm{CCK} / \mathrm{CB}_{1}{ }^{-}$ positive basket cells use $\mathrm{N}$-type $\mathrm{Ca}^{2+}$ channels (Wilson et al., 2001, Hefft and Jonas, 2005). It was also demonstrated that the coupling between $\mathrm{N}$-type $\mathrm{Ca}^{2+}$ channels and the $\mathrm{Ca}^{2+-}$ sensor of exocytosis in CCKpositive basket cells is loose compared to the coupling of $\mathrm{P} / \mathrm{Q}$ type channels and the $\mathrm{Ca}^{2+-}$ sensor of exocytosis in PV-positive basket cells (Hefft and Jonas, 2005; Bucurenciu et al., 2008), probably partly due to the different distribution of these channels in the presynaptic terminal [as shown in the calyx of Held (Wu et al., 1999)]. The loose coupling of these molecules in the presynaptic release machinery might explain the less precise transmission and asynchronous transmitter release of $\mathrm{CCK} / \mathrm{CB}_{1}$-basket cell terminals. In addition, different $\mathrm{Ca}^{2+}$ buffering capacity of the two types of basket cells and the potential presence of different $\mathrm{Ca}^{2+}$ sensors for release with different $\mathrm{Ca}^{2+}$ affinity or $\mathrm{Ca}^{2+}$ binding rate might also contribute to the different fidelity of transmission (Hefft and Jonas, 2005; Eggermann et al., 2012).

Interestingly, Taschenberger et al showed (2002) that during the development of calyx of Held, while the synaptic transmission becomes faster and more efficient, the size of individual active zones decreases. Larger synapses have an initial mixture of $\mathrm{N}, \mathrm{R}$ and $\mathrm{P} / \mathrm{Q}$ types of $\mathrm{Ca}^{2+}$ channels, then $\mathrm{Ca}^{2+}$ channel expression undergoes a developmental switch and smaller synapses will have predominantly $\mathrm{P} / \mathrm{Q}$ type $\mathrm{Ca}^{2+}$ channels (Iwasaki and Takahashi, 1998; Wu et al., 1999; Taschenberger et al., 2002). Therefore, it seems to be that high-fidelity and high-frequency firing might be associated with $\mathrm{P} / \mathrm{Q}$ type $\mathrm{Ca}^{2+}$ channels and smaller, more compact synapses (Taschenberger et al., 2002) similar to that observed here for PV positive synapses.

A synapse with irregular shape has relatively larger perimeter and consequently larger adjacent perisynaptic area than a round shaped synapse. In this perisynaptic annulus of the $\mathrm{CCK} / \mathrm{CB}_{1}$-expressing basket cell boutons, $\mathrm{CB}_{1}$ receptors that can reduce $\mathrm{GABA}$ release depending on the activity of the postsynaptic pyramidal cell (Wilson and Nicoll, 2001), are located in exceptionally large numbers (Nyíri et al., 2005). The irregular shape allows these boutons to increase their perisynaptic annulus area, which is ideal arrangement to express a large number of receptors here. The location, where a vesicle is released can be more variable in an irregular-shaped synapse than in a round or oval synapse, which can influence the diffusion of transmitter in the 
synaptic cleft, that is probably not distributed so evenly in different parts of the irregular-shaped synapse compared to a macular synapse; hence the variability of the postsynaptic response might be also larger in irregular-shaped synapses.

The perforated nature of the excitatory synapses is usually associated with ongoing synaptic plasticity (Geinisman et al., 1993). Interestingly, similar to these observations, $\mathrm{CCK} / \mathrm{CB}_{1}$ basket cells (that frequently have irregular-shaped synapses with perforated-like appearance) are thought to function as "plastic finetuning device”, whereas PV-positive basket cells (that do not have irregular-shaped synapses) release GABA more precisely and act as „clockwork” for oscillations (Freund and Katona, 2007).

$\mathrm{CB}_{1}$-positive basket cells contain the neuropeptide CCK that differentially modulates the output of the two basket cell types, and thought to be stored in dense-core vesicles in the axon terminals (Földy et al., 2007; Lee and Soltesz, 2011). Interestingly, in addition to $\mathrm{CB}_{1}$-positive somatic boutons ( $72 \%$ of $\mathrm{CB}_{1}$-positive somatic boutons have dense core vesicles), we also found dense-core vesicles in a large proportion of PV-positive somatic terminals and axo-axonic boutons ( 29\% of PV-positive somatic boutons and $\sim 52 \%$ of axoaxonic boutons), therefore perisomatic axon terminals cannot be differentiated based on the presence or absence of dense-core vesicles. The content and role of these dense-core vesicles in PV-positive cells is unknown. Occasionally, some atypical axo-axonic boutons in rat and monkey visual cortex were shown to contain the neuropeptide somatostatin, but these somatostatinpositive terminals did not express PV (Gonchar et al., 2002).

In this study, we found that morphological parameters of axo-axonic boutons (shape of bouton, size of mitochondria, shape of synapses, vesicle arrangement) are more similar to those of PV-positive somatic boutons (Figs. 7-9; Table 3), although their size is smaller. They form only one synapse with their target AIS, whereas basket cells often establish more synapses with the innervated somata (Figs. 5 and 6; Table 3). This finding agrees well with data on physiological properties of these cells that are also more similar to PV-positive basket cells [fast-spiking properties with moderate accommodation and reliable transmission (Maccaferri et al., 2000; Szabó et al., 2010)].

\section{Comparison of perisomatic inputs on pyramidal cells in the CA1 and CA3 areas}

We found that morphological parameters of perisomatic boutons were not statistically different between the CA1 and CA3 areas, except that mitochondria of $\mathrm{CB}_{1}$-positive boutons in CA3 occupied a significantly larger proportion of the bouton volume than in $\mathrm{CB}_{1}$-positive boutons in CA1 (Fig. 9, Table 3). The density and proportion of $\mathrm{PV}$ - and $\mathrm{CB}_{1}$-positive inputs on pyramidal cell soma surface were also similar in the two areas. However, pyramidal cell bodies were significantly larger in the CA3 area (their surface was 2.3 times larger), therefore the total number of basket cell inputs were also proportionally larger in this area (60 versus 140 somatic inputs/ pyramidal cell soma in CA1 and CA3, respectively; Table 1 ).

\section{Conclusion}

Here we show the exact convergence ratio of the two basket cell terminals on pyramidal cell somata that are in a critical position to control the frequency and synchrony of action potential generation. Furthermore, we also described fine ultrastructural details of perisomatic boutons that later can be used either for modeling purposes, or to help generate new ideas about energy requirements, peptide content and about the variability of transmission efficacy of these terminals.

Our results clearly demonstrated that interneuron types are not only different in terms of target selectivity, peptide, calcium-binding protein or receptor content and other physiological parameters, but even their fine ultrastructural features are characteristically determined, the reason of which is not fully understood. 


\section{Figures}
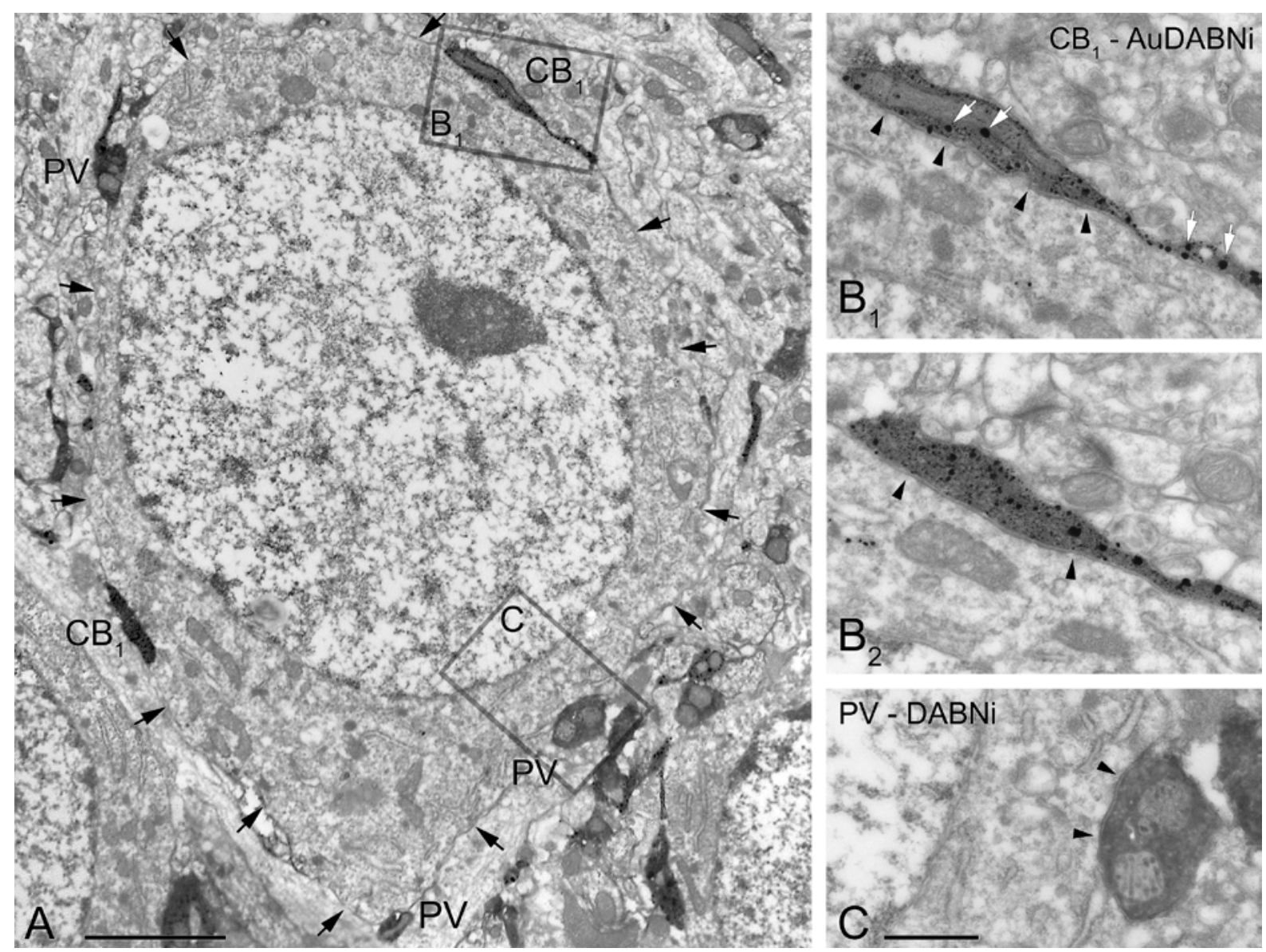

Fig. 1 Convergence of $\mathrm{PV}$ and $\mathrm{CB}_{1}$-positive somatic inputs onto pyramidal somata. Electron micrographs from double labeling immunocytochemical experiments for $\mathrm{PV}$ and $\mathrm{CB}_{1}$ receptor show a CA1 pyramidal cell soma that is innervated by PV-positive and $\mathrm{CB}_{1}$-positive boutons. The density of different somatic inputs was determined by counting these inputs over the somatic membrane through consecutive serial sections, using stereological principles. Arrows in A indicate the soma membrane. The framed areas in A are enlarged in $\mathrm{B}_{1}$ and C. Images of serial sections show the same bouton in $B_{1}$ and $B_{2}$. PV-positive profiles were labeled by homogenous DABNi deposit (C), whereas $\mathrm{CB}_{1}$-positive elements were revealed by $\mathrm{DABNi}$, which is studded with fine metal particles (white arrows, AuDABNi, $\mathrm{B}_{1,2}$ ). Arrowheads in $\mathrm{B}_{1-2}$ and $\mathrm{C}$ indicate presumed edges of synaptic membranes. Compare the characteristic flat shape of the $\mathrm{CB}_{1}$-positive bouton $\left(\mathrm{B}_{1-2}\right)$ with the typically more spherical morphology of the PV-positive terminal (C). Scale bar is $2 \mu \mathrm{m}$ in A and $0.5 \mu \mathrm{m}$ in $\mathrm{C}$ for $\mathrm{B}_{1-2}$ and C. 


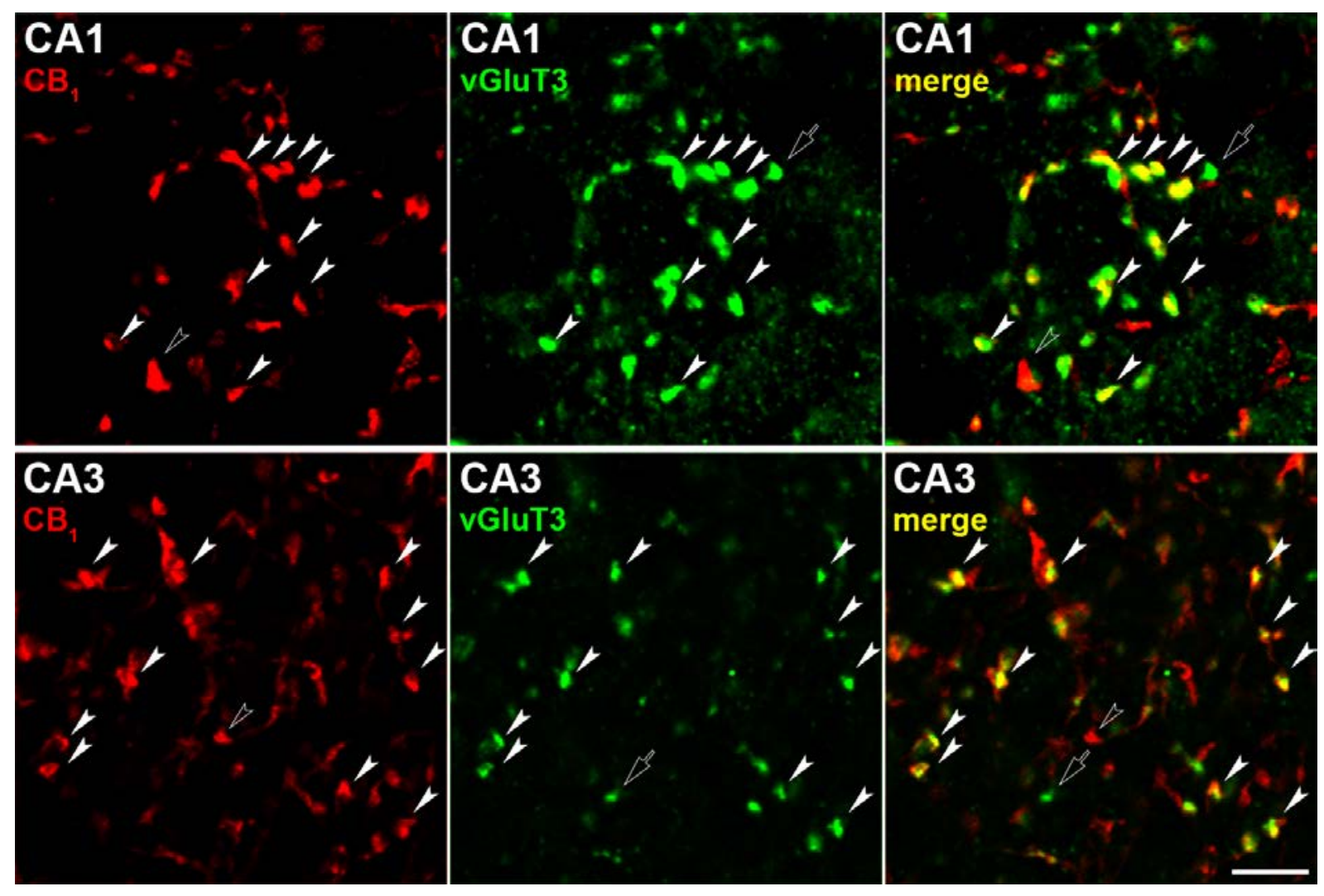

Fig. 2 Confocal images showing that the majority of the $\mathrm{CB}_{1}$ receptor containing (red immunofluorescence) boutons contains vGluT3 (green immunofluorescence) as well in the pyramidal layer of the CA1 (upper row) and CA3 region (lower row) of the hippocampus (double labeled terminals: white arrowheads). Some only $\mathrm{CB}_{1^{-}}$ containing basket cell terminals (empty arrowheads), and only vGluT3-containing basket cell terminals (empty arrows) are also present. Scale bar: $5 \mu \mathrm{m}$. 

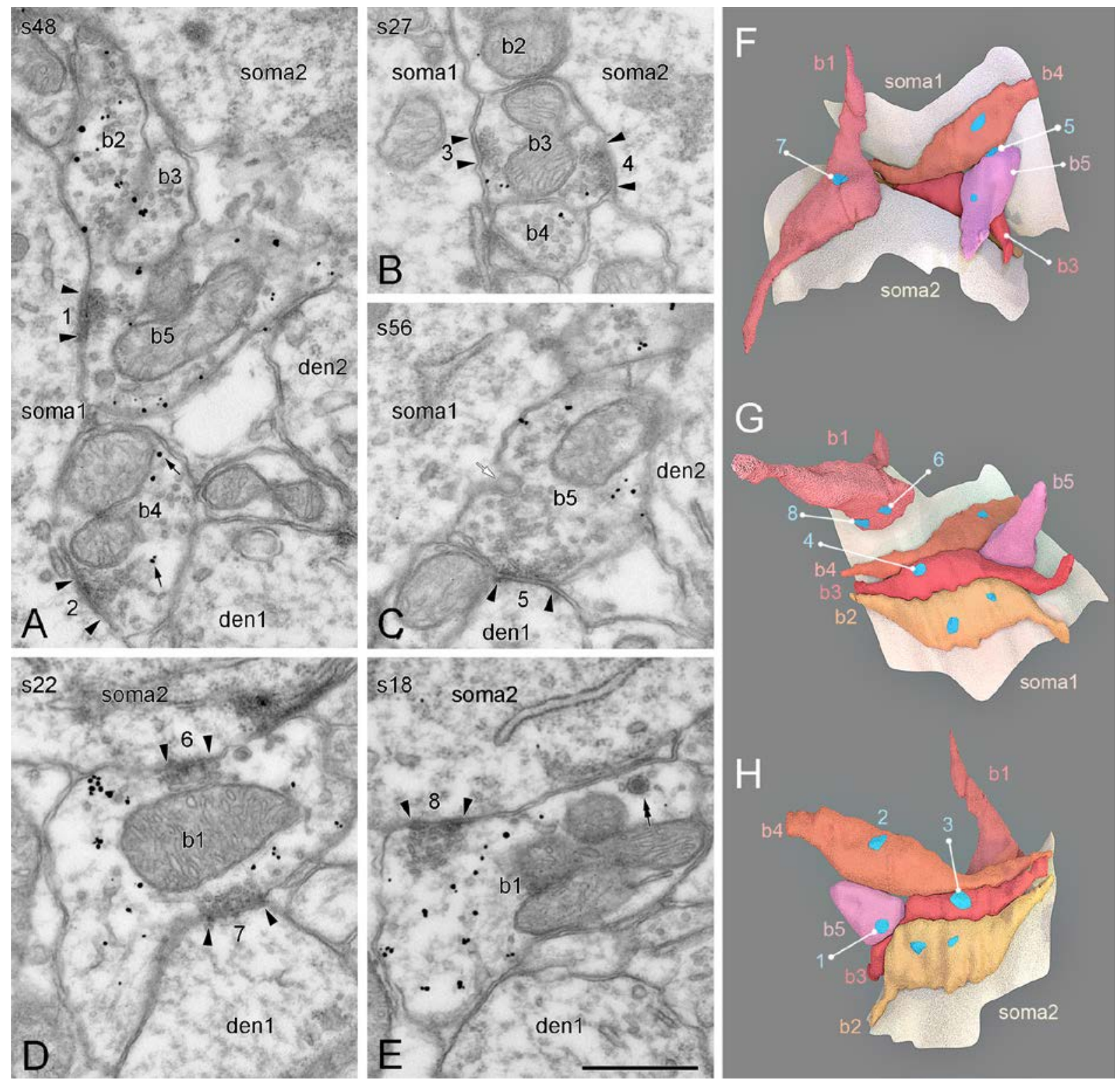

Fig. 3 3D-reconstruction of PV-positive somatic terminals. A-E: Electron micrographs of five PV-positive terminals (b1-5) located between two pyramidal somata (soma1 and 2) in CA1 area. PV is labeled by silverintensified gold particles (arrows in A). These terminals were 3D-reconstructed from a series of consecutive serial sections (s18-56: the number of the section in the examined series). Three different views of the 3D reconstruction of the same terminals are shown in $\mathrm{F}-\mathrm{H}$, where the boutons are indicated by different warm colors, whereas reconstructed parts of the somatic membranes are shown as light yellow areas. Membrane of soma1 / soma2 is removed in $\mathrm{H}$ and G for better visibility. PV-positive boutons form small synapses (in A-E arrowheads label the edges of synaptic membranes) which display macular shape (blue areas in F-H) and dense accumulation of vesicles at the presynaptic membrane (A-E). Individual synapses are indicated by the same numbers in the electron micrographs and 3D-reconstructions. All of the PV-positive boutons shown here diverge to more postsynaptic profiles, which are two somata (e. g. b3 bouton, B) or a soma and one or two dendrite(s) (den1 and 2) (e.g. b1 bouton, D; b5 bouton A and C). Boutons can form more synapses with the same soma as well ( $\mathrm{D}$ and $\mathrm{E}$, different synapses of the "b1" bouton onto soma 2). PV-positive boutons may contain dense core vesicle (double arrow in E) and invaginations (white arrow in C). Scale bar is $0.5 \mu \mathrm{m}$ for A-E 

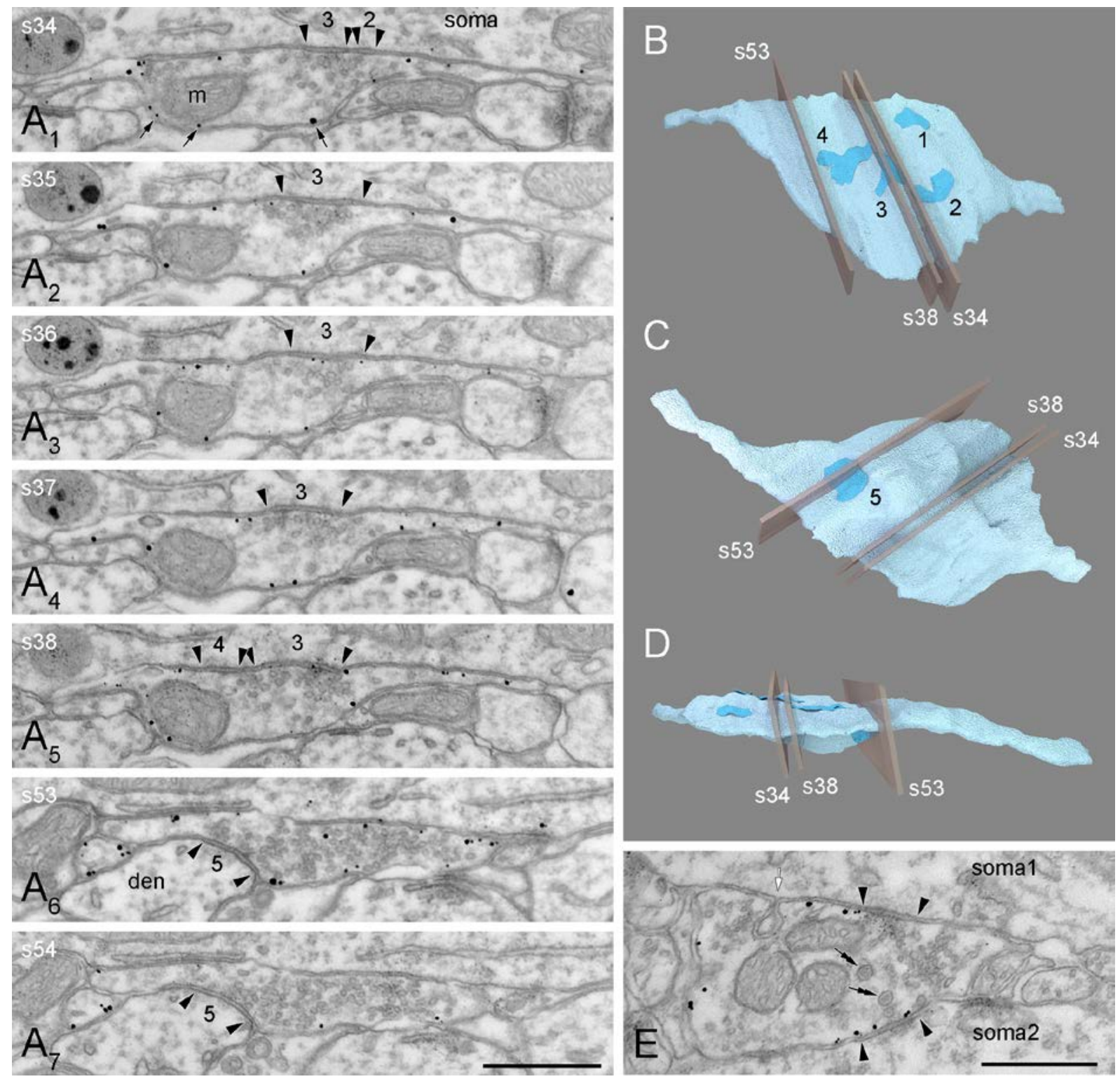

Fig. 4 3D reconstruction of a $\mathrm{CB}_{1}$-positve terminal. $\mathrm{A}_{1-7}$ : Serial electron micrographs of a reconstructed $\mathrm{CB}_{1^{-}}$ positive somatic terminal (section, s 34-38 and 53-54 of a series of consecutive series, $40 \mathrm{~nm}$-thick sections). $\mathrm{CB}_{1}$ receptor is labeled by silver-intensified gold particles that are attached to plasma membranes of the bouton (arrows in $A_{1}$ ). Arrowheads label synapse-edges. Vesicles are less densely clustered at synaptic membranes of $\mathrm{CB}_{1}$-positive boutons than that of PV-positive terminals (compare with Fig. 3). Synaptic membrane segments, where no vesicles seen close to the membrane $\left(A_{3}\right)$ are continuous with segments where vesicles present (e.g. $\left.A_{4}\right)$. In addition to synapses innervating the soma $\left(A_{1-5}\right)$ this bouton forms a synapse with a dendrite as well $\left(A_{6-}\right.$ 7). 3D-reconstruction of the same bouton is shown in B-D from three different angles. Notice the characteristic flat shape of the terminal (D). Sections s34, s38 and s53, shown in A1-7 are indicated by partially transparent grey plains in the 3D reconstructions. B: Some synapses innervating the somata (2, 3 and 4, indicated by dark blue areas) are very close to and not clearly separated from each other, but for demonstration purposes we labeled them separately. The closeness of synapse 2-3 and 3-4 are demonstrated in $A_{1}$ and $A_{5}$, respectively. C: Synapse innervating the dendrite (den in $\mathrm{A}_{6-7}$ ) on the other side of the bouton (5, dark blue area). E: Dense core vesicles (double arrows) and a somatic protrusion into the plasma membrane of the terminal (white arrow) are present in another $\mathrm{CB}_{1}$-positive bouton. This bouton forms synapses with two somata (soma1 and 2, arrowheads). In this section vesicle-free segment of the synapse with soma 2 is seen, whereas synaptic vesicles are clustered at synapse formed with soma1. Scale bar is $0.5 \mu \mathrm{m}$ for images $\mathrm{A}_{1-7}$ and $\mathrm{E}$. 

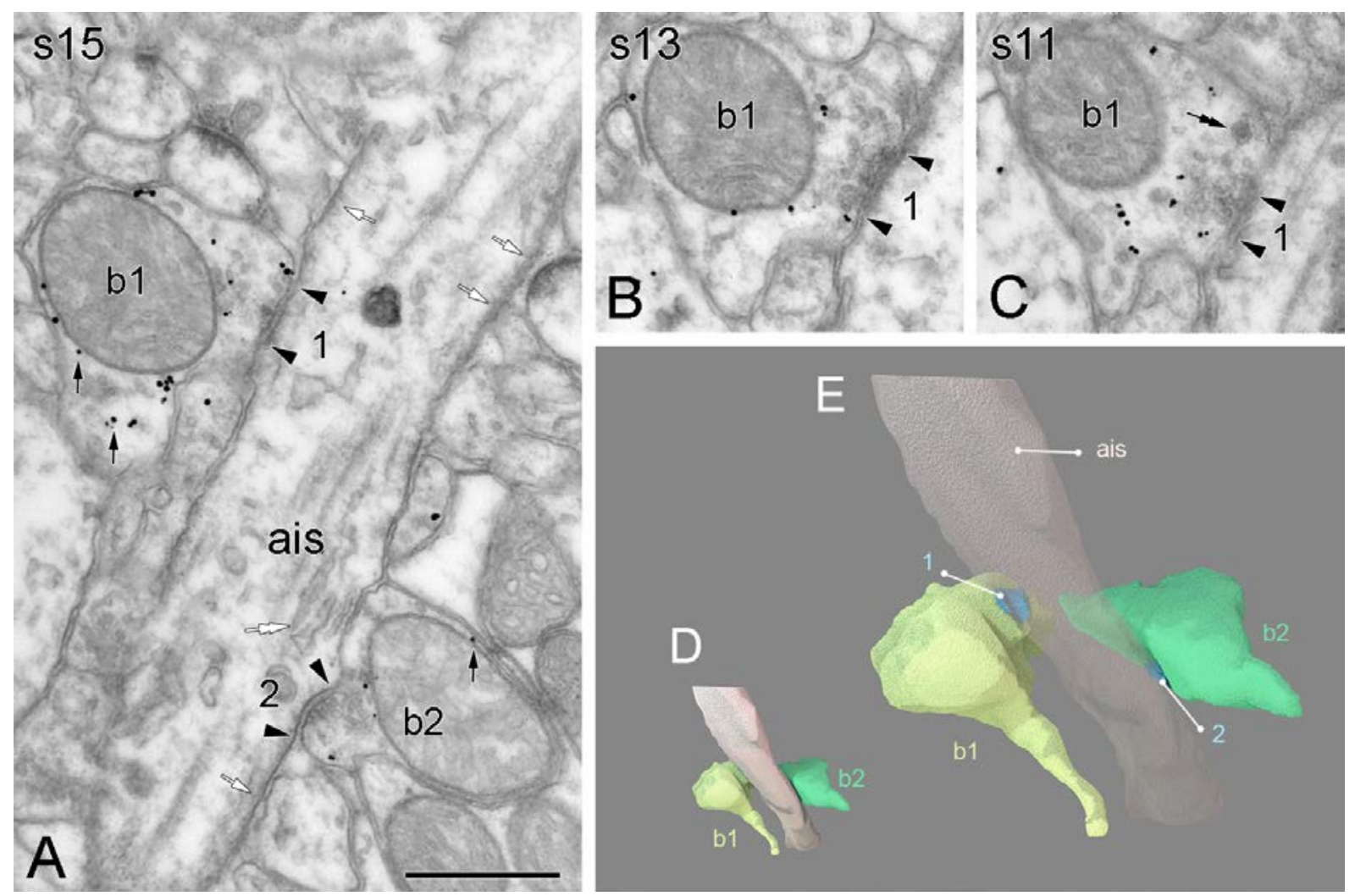

Fig. 5 3D reconstruction of axo-axonic terminals. A-C: Electron micrographs of two parvalbumin-positive axoaxonic terminals (b1, b2) that establish synapses on an axon initial segment (ais). Arrowheads indicate synapseedges. Parvalbumin is labeled by silver-intensified gold particles (arrows in A). The axon initial segment was identified by its characteristic membrane undercoating (white arrows in A), bundles of microtubules and stacked endoplasmic cisterns (white double arrow in A). Synaptic vesicles in the boutons are clustered at the presynaptic membranes. C: A dense core vesicle is indicated by a double arrow. Axo-axonic boutons form only one synapses (1 and 2, blue areas in E) with their postsynaptic axon initial segment. D and E: 3D reconstruction of the same boutons (b1, b2) and the innervated axon initial segment (ais). Scale bar is $0.5 \mu \mathrm{m}$ for images A-C. 


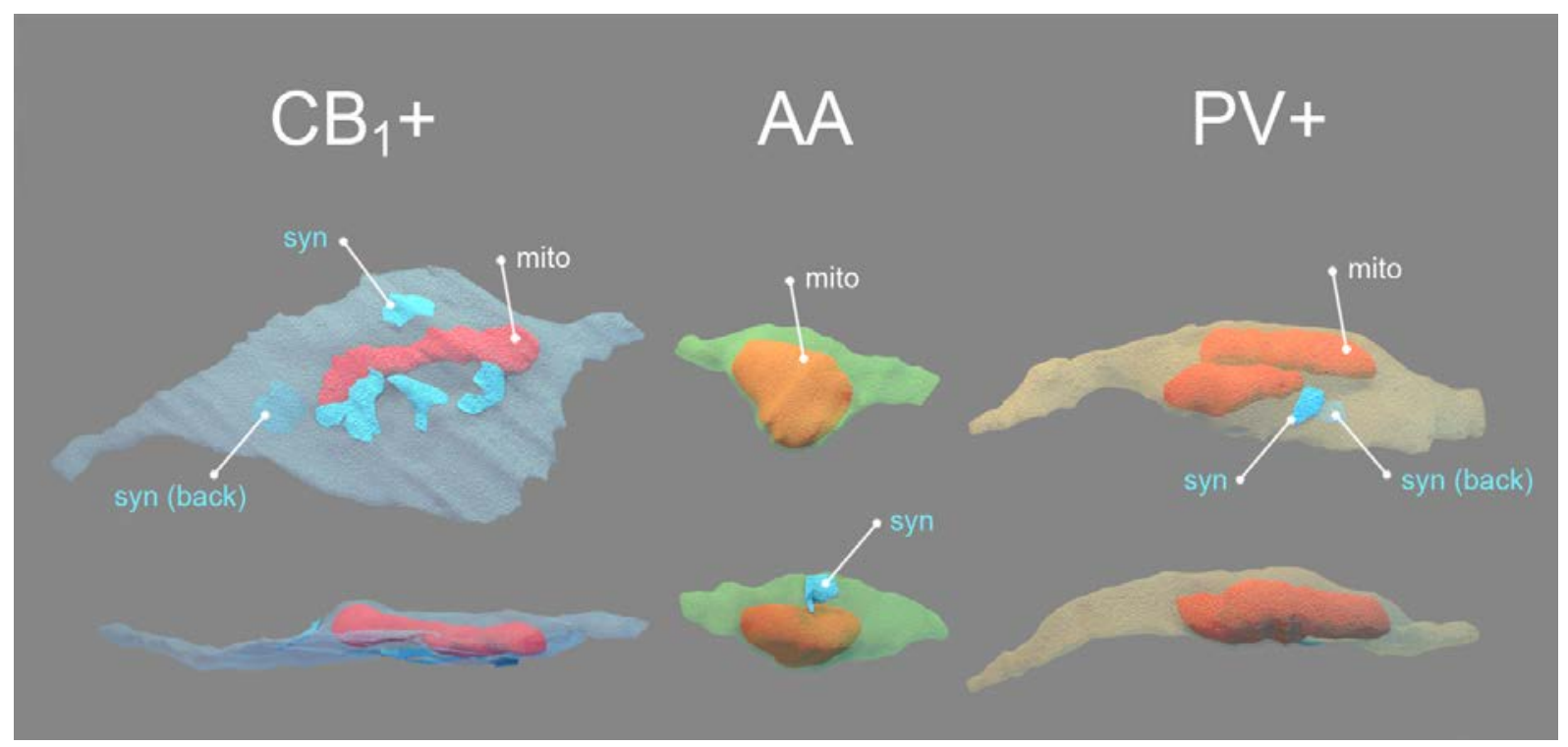

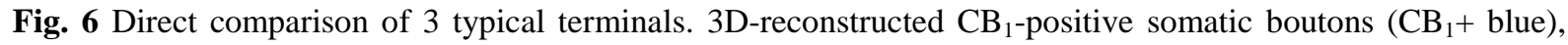
axo-axonic terminals (AA, green) and PV-positive somatic boutons (PV+, orange) show characteristic differences in their morphological properties. Three boutons with typical morphology are shown from two orthogonal directions. Synaptic membranes are shown as blue areas (syn). The bouton membranes were made partially transparent to reveal mitochondria (mito, warm colors) inside the boutons and synapses on the other side of the terminals (syn, back). Axo-axonic boutons are usually smaller than somatic boutons. $\mathrm{CB}_{1}$-positive boutons are flat compared to PV-positive somatic and axo-axonic boutons which are more spherical. Axo-axonic terminals form only one synapse, whereas somatic boutons usually establish more synapses. PV-positive somatic and axo-axonic boutons possess small, macular synapses, whereas synapses of $\mathrm{CB}_{1}$-positive somatic terminals are larger and have synapses with more complex shapes. Mitochondria occupy larger volume in PV-positive somatic boutons and axo-axonic terminals compared to $\mathrm{CB}_{1}$-positive somatic boutons. 


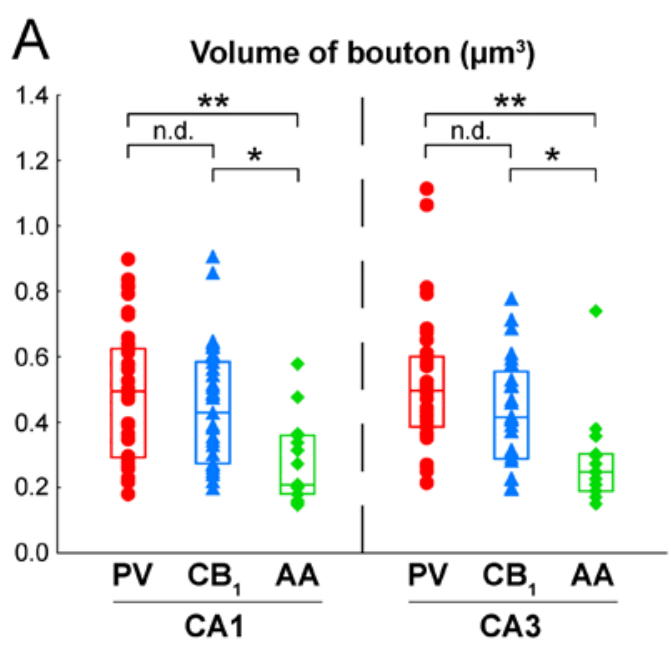

C Volume of all mitochondria in bouton/ volume of bouton

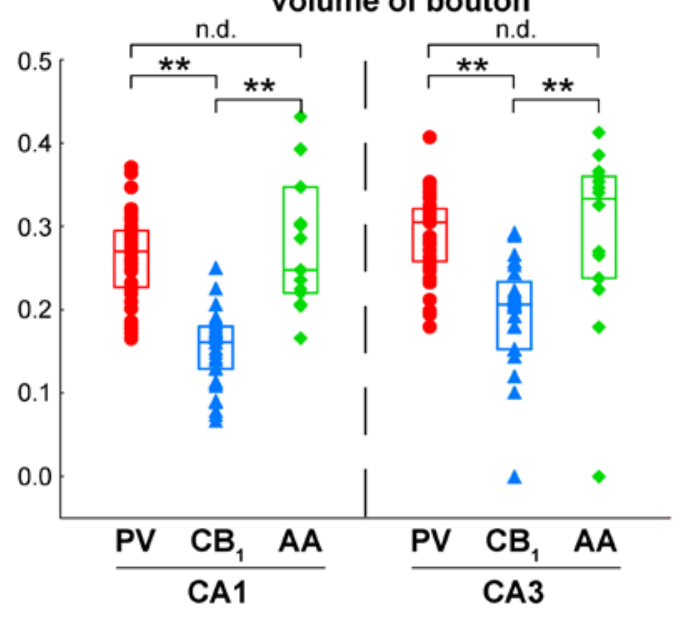

\section{B Surface/ volume of bouton $\left(\mu \mathrm{m}^{2} / \mu \mathrm{m}^{3}\right)$}

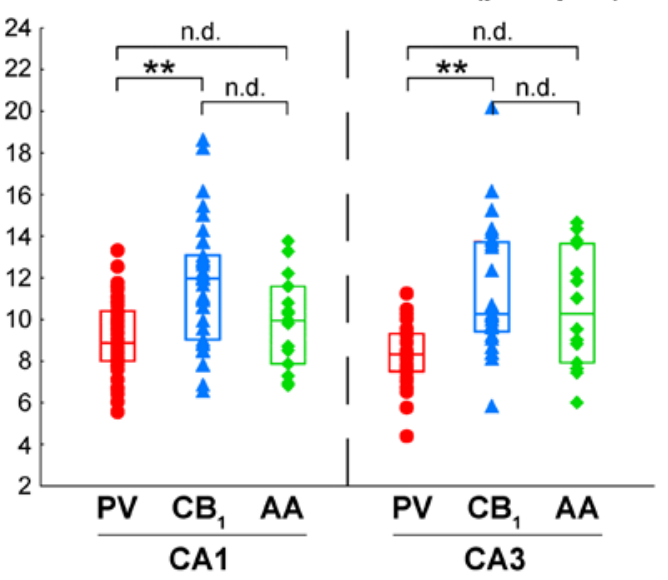

D Total synaptic areas $\left(\mu \mathrm{m}^{2}\right)$

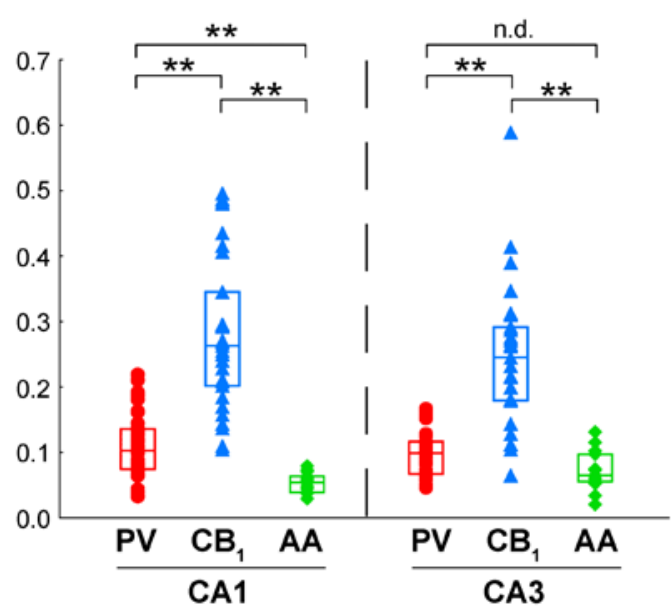

- Median, $\square$ Interquartile range, $\bullet \Delta$ Raw data

Fig. 7 Ultrastructural parameters of reconstructed perisomatic terminals show characteristic differences. Raw data distributions, medians (horizontal bar) and interquartile ranges (framed area) of measured ultrastructural parameters are shown. Asterisks indicate significant difference (*: $\mathrm{p}<0.05 ; * *$ : $\mathrm{p}<0.01)$; n.d, no significant difference could be found. A: Ranges of volumes of different types of somatic boutons $\left(\mathrm{PV}, \mathrm{CB}_{1}\right)$ are similar; whereas axo-axonic boutons (AA) are smaller than somatic boutons, both in CA1 and CA3 areas. B: The surface/volume ratio of $\mathrm{CB}_{1}$-positive boutons is larger than that of PV-positive boutons because of their less spherical morphology. C: Mitochondria of PV-positive somatic boutons and axo-axonic terminals occupy significantly larger volume inside the bouton than that of $\mathrm{CB}_{1}$-positive boutons. $\mathrm{D}$ : Total synaptic areas of $\mathrm{CB}_{1}$ positive somatic boutons are significantly larger than that of PV-positive boutons. 

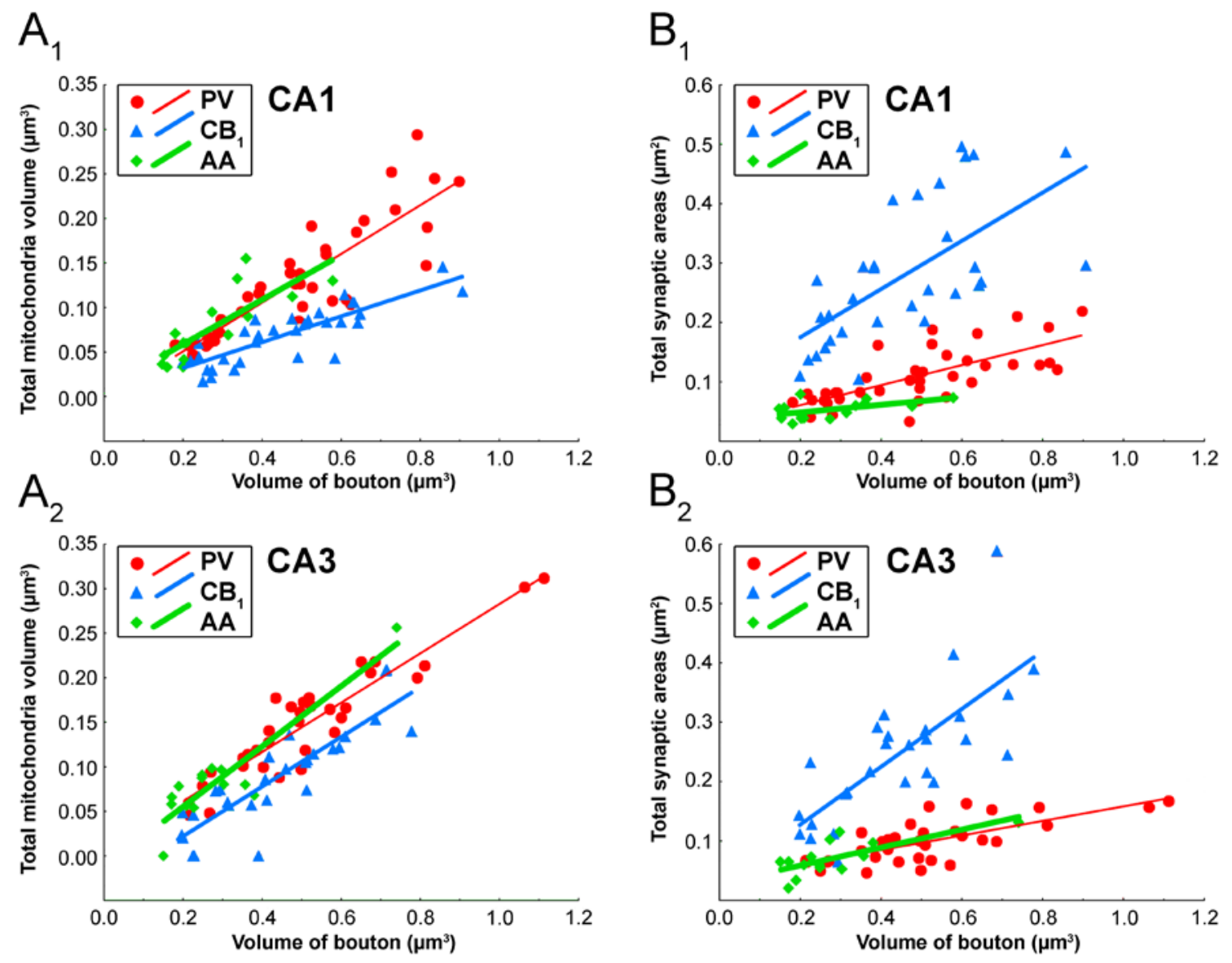

Fig. 8 The correlation of the volume of perisomatic boutons with both the total mitochondrial volume and total synaptic areas was tested (Spearman Rank correlation). Raw data of PV-positive somatic boutons (red circles), $\mathrm{CB}_{1}$-positive somatic terminals (blue triangles) as well as axo-axonic boutons (AA, green diamonds) in CA1 ( $\mathrm{A}_{1}$, $\left.B_{1}\right)$ and CA3 $\left(A_{2}, B_{2}\right)$ are shown. $A_{1-2}$ : Total mitochondria volume shows a significant correlation with the volume of the boutons. PV-positive somatic and axo-axonic boutons possess larger mitochondria compared to $\mathrm{CB}_{1}$-positve boutons with similar volume. $\mathrm{B}_{1-2}$ : Correlation between the total size of synapses and the volume of the bouton was significant in all cases except for AA boutons in $\mathrm{CA}$. $\mathrm{CB}_{1}$-positive boutons possess larger total synaptic membranes than PV-positive somatic and axo-axonic boutons. Note that correlation lines of axo-axonic boutons almost overlap with that of PV-positive somatic boutons. 


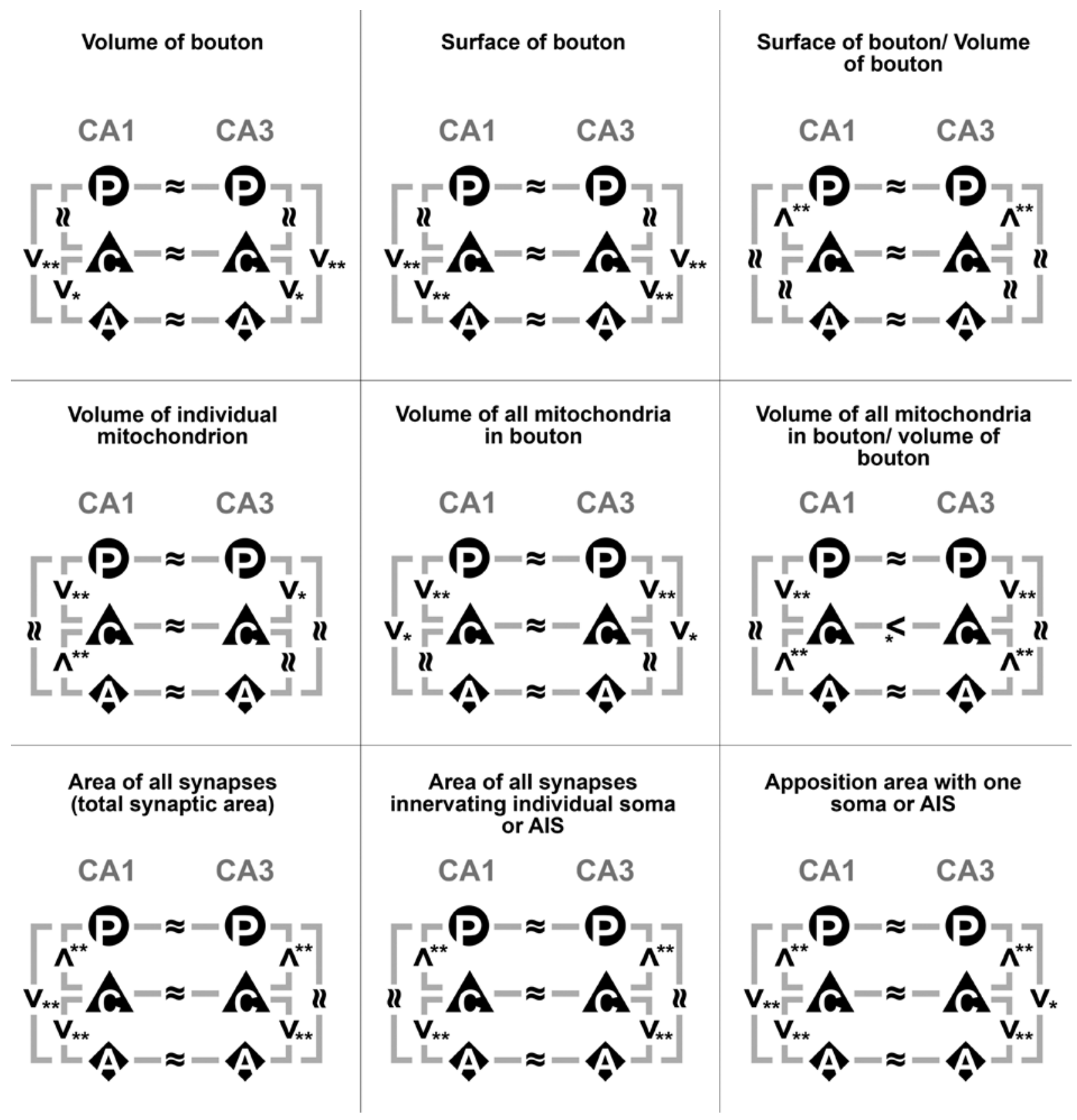

Fig. 9 Statistical comparison of measured ultrastructural parameters of PV-positive somatic terminals (circle with $\mathrm{P}$ ), $\mathrm{CB}_{1}$-positive somatic boutons (triangle with $\mathrm{C}$ ) and axo-axonic terminals (diamond with A). Relational sign $(>)$ show the direction of statistically significant differences between groups at $\mathrm{p}<0.05(*)$ or at $\mathrm{p}<0.01(* *)$ significance levels (after Bonferroni’s correction for multiple comparison). Equal sign $(\approx)$ shows no significant difference. Area of all synapses (total synaptic area) includes synapses of all targets of a given bouton. 


\section{Tables}

Table 1 Convergence of PV- or $\mathrm{CB}_{1}$-positive and double-negative somatic inputs onto hippocampal pyramidal cell bodies.

CA1

mouse 1

mouse 2

mouse 3

\begin{tabular}{|c|c|c|c|c|c|c|c|c|c|}
\hline total number of innuts/ 100 um $^{2}$ & \multirow{2}{*}{\multicolumn{3}{|c|}{15.2 ( $\mathrm{n}=3$ somata) }} & \multicolumn{3}{|c|}{$20(n=4$ somata $)$} & \multicolumn{3}{|c|}{$22.7(n=4$ somata $)$} \\
\hline PV-positive inputs/ $100 \mu \mathrm{m}^{2}$ & & & & \multicolumn{3}{|c|}{$13.1(\mathrm{n}=4$ somata $)$} & \multicolumn{3}{|c|}{$13.3(n=4$ somata $)$} \\
\hline $\mathrm{CB}_{1}$-positive inputs/ $100 \mu^{2}$ & \multicolumn{3}{|c|}{$6.5(n=3$ somata $)$} & \multicolumn{3}{|c|}{$6.9(n=4$ somata $)$} & \multicolumn{3}{|c|}{$9.1(n=4$ somata $)$} \\
\hline double negative inputs/ $100 \mu^{2}$ & \multicolumn{3}{|c|}{$0.4(n=3$ somata $)$} & \multicolumn{3}{|c|}{$0(\mathrm{n}=4$ somata $)$} & \multicolumn{3}{|c|}{$0.3(n=4$ somata $)$} \\
\hline \% of PV-positive inputs & \multicolumn{3}{|c|}{55} & \multicolumn{3}{|c|}{65.4} & \multicolumn{3}{|c|}{58.6} \\
\hline$\%$ of $\mathrm{CB}_{1}$-positive inputs & \multicolumn{3}{|c|}{42.5} & \multicolumn{3}{|c|}{34.6} & \multicolumn{3}{|c|}{40} \\
\hline \% of double negative inputs & \multicolumn{3}{|c|}{2.5} & \multicolumn{3}{|c|}{0} & \multicolumn{3}{|c|}{1.4} \\
\hline $\begin{array}{r}\text { soma surface } \\
\left(\mu \mathrm{m}^{2}, \text { median is bold }\right)^{\mathrm{a}}\end{array}$ & 343 & 345 & 416 & 261 & 286 & 310 & 297 & 312 & 323 \\
\hline total number of inputs/ soma & 52 & 53 & 63 & 52 & 57 & 62 & 67 & 71 & 73 \\
\hline PV-positive inputs/ soma & 29 & 29 & 35 & 34 & 37 & 41 & 39 & 41 & 43 \\
\hline $\mathrm{CB}_{1}$-positive inputs/ soma & 22 & 23 & 27 & 18 & 20 & 21 & 27 & 28 & 29 \\
\hline Double negative inputs/ soma & 1 & 1 & 2 & 0 & $\mathbf{0}$ & 0 & 1 & 1 & 1 \\
\hline CA3 & \multicolumn{3}{|c|}{ mouse 1} & \multicolumn{3}{|c|}{ mouse 2} & \multicolumn{3}{|c|}{ mouse 3} \\
\hline total number of inputs/ $100 \mu \mathrm{m}^{2}$ & \multirow{4}{*}{\multicolumn{3}{|c|}{$\begin{array}{c}17.9(\mathrm{n}=3 \text { somata }) \\
11.6(\mathrm{n}=3 \text { somata }) \\
6.3(\mathrm{n}=3 \text { somata }) \\
0(\mathrm{n}=3 \text { somata })\end{array}$}} & \multirow{4}{*}{\multicolumn{3}{|c|}{$\begin{array}{c}20.4 \text { ( } \mathrm{n}=3 \text { somata) } \\
12.2 \text { ( } \mathrm{n}=3 \text { somata) } \\
7.6 \text { ( } \mathrm{n}=3 \text { somata }) \\
0.5 \text { ( } \mathrm{n}=3 \text { somata })\end{array}$}} & \multirow{4}{*}{\multicolumn{3}{|c|}{$\begin{array}{c}24.8(n=4 \text { somata }) \\
15.4(n=4 \text { somata }) \\
7.5(n=4 \text { somata }) \\
1.9(n=4 \text { somata })\end{array}$}} \\
\hline PV-positive inputs/ $100 \mu \mathrm{m}^{2}$ & & & & & & & & & \\
\hline $\mathrm{CB}_{1}$-positive inputs/ $100 \mathrm{\mu m}^{2}$ & & & & & & & & & \\
\hline double negative inputs/ $100 \mu^{2}$ & & & & & & & & & \\
\hline \% of PV-positive inputs & \multicolumn{3}{|c|}{64.9} & \multicolumn{3}{|c|}{60} & \multicolumn{3}{|c|}{62.3} \\
\hline$\%$ of $\mathrm{CB}_{1}$-positive inputs & \multicolumn{3}{|c|}{35.1} & \multicolumn{3}{|c|}{37.3} & & 30.2 & \\
\hline$\%$ of double negative inputs & & 0 & & & 2.7 & & & 7.5 & \\
\hline $\begin{array}{r}\text { soma surface } \\
\left(\mu \mathrm{m}^{2}, \text { median is bold }\right)^{\mathrm{a}}\end{array}$ & 782 & 797 & 861 & & $638^{b}$ & & & $687^{b}$ & \\
\hline total number of inputs/ soma & 140 & 143 & 154 & & 130 & & & 170 & \\
\hline PV-positive inputs/ soma & 91 & 93 & 100 & & 78 & & & 106 & \\
\hline CB $_{1}$-positive inputs/ soma & 49 & 50 & 54 & & 49 & & & 51 & \\
\hline Double negative inputs/ soma & 0 & $\mathbf{0}$ & 0 & & 3 & & & 13 & \\
\hline
\end{tabular}

a: Three somata are tested in the CA1 of all mice and three somata are tested in the CA3 of mouse 1, the data of which are shown separately.

b: Total somatic surface areas of CA3 pyramidal cells were measured only in mouse 1, therefore, these data are calculated values based on measured values of CA1 pyramidal cell somata of the given mouse and on CA1-CA3 difference in mouse 1. 
Table 2 Colocalization of $\mathrm{CB}_{1}$ and vGluT3 in hippocampal perisomatic boutons in pyramidal cell layers of CA1 and CA3

\begin{tabular}{l|rrr|rrr|} 
& \multicolumn{3}{|l|}{$\begin{array}{l}\text { Testing of } \mathbf{C B}_{\mathbf{1}}+\text { somatic } \\
\text { terminals }\end{array}$} & \multicolumn{3}{l|}{$\begin{array}{l}\text { Testing of vGluT3+ somatic } \\
\text { terminals }\end{array}$} \\
\hline CA1 area & CB $_{\mathbf{1}}+$ & vGluT3+ & $\mathbf{9}$ & vGluT3+ & CB $_{\mathbf{1}}+$ & $\mathbf{\%}$ \\
\hline Mouse 1 (24-day-old) & 94 & 76 & $\mathbf{8 0 . 9}$ & 188 & 179 & $\mathbf{9 5 . 2}$ \\
Mouse 2 (29-day-old) & 68 & 55 & $\mathbf{8 0 . 9}$ & 121 & 120 & $\mathbf{9 9 . 2}$ \\
Mouse 3 (29-day-old) & 49 & 41 & $\mathbf{8 3 . 7}$ & 107 & 107 & $\mathbf{1 0 0 . 0}$ \\
Mouse 4 (31-day-old) & 112 & 103 & $\mathbf{9 2 . 0}$ & 148 & 137 & $\mathbf{9 2 . 6}$ \\
Mouse 5 (31-day-old) & 74 & 65 & $\mathbf{8 7 . 8}$ & 154 & 145 & $\mathbf{9 4 . 2}$ \\
Mouse 6 (60-day-old) & 69 & 59 & $\mathbf{8 5 . 5}$ & 95 & 95 & $\mathbf{1 0 0 . 0}$ \\
\hline
\end{tabular}

\begin{tabular}{l|rrr|rrr|}
\hline CA3 area & CB $_{\mathbf{1}}+$ & vGluT3+ & $\mathbf{9}$ & vGluT3+ & CB $_{\mathbf{1}}+$ & \% \\
\hline Mouse 2 (29-day-old) & 75 & 73 & $\mathbf{9 7 . 3}$ & 133 & 119 & $\mathbf{8 9 . 5}$ \\
Mouse 3 (29-day-old) & 83 & 79 & $\mathbf{9 5 . 2}$ & 73 & 64 & $\mathbf{8 7 . 7}$ \\
Mouse 6 (60-day-old) & 82 & 77 & $\mathbf{9 3 . 9}$ & 90 & 83 & $\mathbf{9 2 . 2}$ \\
\hline
\end{tabular}


Table 3 Measured ultrastructural parameters of perisomatic boutons

\begin{tabular}{|c|c|c|c|c|c|c|c|}
\hline & & PV CA1 & $\mathrm{CB}_{1} \mathrm{CA1}$ & AA CA1 & PV CA3 & $\mathrm{CB}_{1} \mathrm{CA} 3$ & AA CA3 \\
\hline \multirow{4}{*}{$\begin{array}{l}\text { Volume of } \\
\text { bouton }\left(\mu^{3}\right)\end{array}$} & $\mathrm{n}^{\mathrm{a}}$ & 38 & 33 & 15 & 33 & 28 & 14 \\
\hline & Median & 0.4943 & 0.4289 & 0.2087 & 0.4960 & 0.4148 & 0.2479 \\
\hline & Lower Quartile & 0.2923 & 0.2736 & 0.1805 & 0.3858 & 0.2881 & 0.1893 \\
\hline & Upper Quartile & 0.6246 & 0.5841 & 0.3594 & 0.6006 & 0.5547 & 0.3028 \\
\hline \multirow{4}{*}{\multicolumn{2}{|c|}{ Surface of bouton $\left(\mu \mathrm{m}^{2}\right)$}} & 38 & 33 & 15 & 33 & 28 & 14 \\
\hline & & 4.183 & 4.618 & 2.344 & 4.124 & 4.573 & 2.534 \\
\hline & & 3.292 & 3.886 & 1.971 & 3.133 & 3.356 & 2.156 \\
\hline & & 5.277 & 5.636 & 2.828 & 4.672 & 5.582 & 2.907 \\
\hline \multirow{4}{*}{\multicolumn{2}{|c|}{$\begin{array}{l}\text { Surface of bouton/ volume of } \\
\text { bouton }\left(\mu^{2} / \mu^{3}\right)\end{array}$}} & 38 & 33 & 15 & 33 & 28 & 14 \\
\hline & & 8.887 & 11.965 & 9.948 & 8.329 & 10.265 & 10.281 \\
\hline & & 8.023 & 9.032 & 7.869 & 7.509 & 9.428 & 7.925 \\
\hline & & 10.410 & 13.084 & 11.587 & 9.312 & 13.713 & 13.640 \\
\hline \multirow{4}{*}{\multicolumn{2}{|c|}{$\begin{array}{l}\text { Volume of individual } \\
\text { mitochondrion }\left(\mu^{3}\right)\end{array}$}} & 63 & 58 & 17 & 55 & 42 & 16 \\
\hline & & 0.0714 & 0.0298 & 0.0587 & 0.0782 & 0.0504 & 0.0791 \\
\hline & & 0.0499 & 0.0215 & 0.0414 & 0.0470 & 0.0332 & 0.0576 \\
\hline & & 0.1074 & 0.0495 & 0.0709 & 0.1184 & 0.0762 & 0.0892 \\
\hline \multirow{4}{*}{\multicolumn{2}{|c|}{$\begin{array}{l}\text { Volume of all mitochondria in } \\
\text { bouton }\left(\mu^{3}\right)\end{array}$}} & 38 & 33 & 15 & 33 & 28 & 14 \\
\hline & & 0.1190 & 0.0734 & 0.0692 & 0.1506 & 0.0801 & 0.0791 \\
\hline & & 0.0721 & 0.0423 & 0.0414 & 0.1009 & 0.0528 & 0.0582 \\
\hline & & 0.1652 & 0.0863 & 0.1123 & 0.1770 & 0.1209 & 0.0909 \\
\hline \multirow{4}{*}{\multicolumn{2}{|c|}{$\begin{array}{l}\text { Volume of all mitochondria in } \\
\text { bouton/volume of bouton } \\
\left(\mu^{3} / \mathrm{m}^{3}\right)\end{array}$}} & 38 & 33 & 15 & 33 & 28 & 14 \\
\hline & & 0.270 & 0.161 & 0.248 & 0.305 & 0.206 & 0.333 \\
\hline & & 0.227 & 0.129 & 0.220 & 0.258 & 0.153 & 0.238 \\
\hline & & 0.295 & 0.180 & 0.347 & 0.321 & 0.234 & 0.360 \\
\hline \multirow{4}{*}{\multicolumn{2}{|c|}{$\begin{array}{l}\text { Area of all synapses of the } \\
\text { bouton (total synaptic area, } \\
\text { includes synapses of all } \\
\text { targets of a given bouton; } \\
\mu^{2} \text { ) }\end{array}$}} & 39 & 31 & 15 & 33 & 27 & 14 \\
\hline & & 0.1025 & 0.2627 & 0.0543 & 0.0990 & 0.2451 & 0.0649 \\
\hline & & 0.0742 & 0.2015 & 0.0388 & 0.0672 & 0.1793 & 0.0554 \\
\hline & & 0.1357 & 0.3453 & 0.0636 & 0.1165 & 0.2915 & 0.0971 \\
\hline \multirow{4}{*}{\multicolumn{2}{|c|}{$\begin{array}{l}\text { Area of all synapses } \\
\text { innervating individual soma } \\
\text { or AIS }\left(\mu \mathrm{m}^{2}\right)\end{array}$}} & 52 & 36 & 15 & 42 & 27 & 14 \\
\hline & & 0.0661 & 0.2282 & 0.0543 & 0.0646 & 0.2320 & 0.0649 \\
\hline & & 0.0456 & 0.1622 & 0.0388 & 0.0464 & 0.1434 & 0.0554 \\
\hline & & 0.0811 & 0.2597 & 0.0636 & 0.0862 & 0.2850 & 0.0757 \\
\hline \multirow{4}{*}{\multicolumn{2}{|c|}{$\begin{array}{l}\text { Apposition area with one } \\
\text { soma or AIS }\left(\mu^{2}\right)\end{array}$}} & 53 & 37 & 15 & 43 & 28 & 14 \\
\hline & & 1.200 & 1.800 & 0.317 & 0.959 & 1.735 & 0.358 \\
\hline & & 0.720 & 1.093 & 0.172 & 0.348 & 1.149 & 0.209 \\
\hline & & 1.533 & 2.000 & 0.434 & 1.326 & 2.194 & 0.438 \\
\hline
\end{tabular}

${ }^{\mathrm{a}}$ : All data were collected from three mice in a representative manner. None of the features were different among the different animals and therefore, they were pooled and presented together. Data in this table are presented in the same order in all categories. 


\section{Acknowledgement}

We thank Dr. Kenneth G. Baimbridge for the rabbit anti-PV antibody and Dr. Ken Mackie (supported by

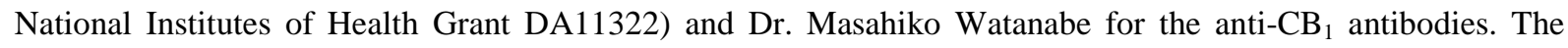
excellent technical assistance of Katalin Lengyel, Emőke Szépné Simon, Katalin Iványi and Győző Goda is also gratefully acknowledged. This work was supported by the National Institutes of Health (grant number NS030549), National Office for Research and Technology - Hungarian Scientific Research Fund (NKTHOTKA, grant number CNK77793, K83251) and European Research Council (grant number ERC-2011-ADG294313, SERRACO). G.N. was supported by a János Bolyai Research Scholarship.

\section{References}

Acsády L, Arabadzisz D, Freund TF (1996) Correlated morphological and neurochemical features identify different subsets of vasoactive intestinal polypeptide-immunoreactive interneurons in rat hippocampus. Neuroscience 73:299-315.

Armstrong C, Soltesz I (2012) Basket cell dichotomy in microcircuit function. J Physiol 590:683-694.

Bartos M, Elgueta C (2012) Functional characteristics of parvalbumin- and cholecystokinin-expressing basket cells. J Physiol 590:669-681.

Berod A, Hartman BK, Pujol JF (1981) Importance of fixation in immunohistochemistry: use of formaldehyde solutions at variable $\mathrm{pH}$ for the localization of tyrosine hydroxylase. J Histochem Cytochem 29:844850 .

Billups B, Forsythe ID (2002) Presynaptic mitochondrial calcium sequestration influences transmission at mammalian central synapses. J Neurosci 22:5840-5847.

Biró AA, Holderith NB, Nusser Z (2006) Release probability-dependent scaling of the postsynaptic responses at single hippocampal GABAergic synapses. J Neurosci 26:12487-12496.

Bodor AL, Katona I, Nyíri G, Mackie K, Ledent C, Hájos N, Freund TF (2005) Endocannabinoid signaling in rat somatosensory cortex: laminar differences and involvement of specific interneuron types. J Neurosci 25:6845-6856.

Bodor AL, Giber K, Rovó Z, Ulbert I, Acsády L (2008) Structural correlates of efficient GABAergic transmission in the basal ganglia-thalamus pathway. J Neurosci 28:3090-3102.

Branco T, Marra V, Staras K (2010) Examining size-strength relationships at hippocampal synapses using an ultrastructural measurement of synaptic release probability. J Struct Biol 172:203-210.

Bucurenciu I, Kulik A, Schwaller B, Frotscher M, Jonas P (2008) Nanodomain coupling between Ca2+ channels and $\mathrm{Ca} 2+$ sensors promotes fast and efficient transmitter release at a cortical GABAergic synapse. Neuron 57:536-545.

Chan-Palay V (1972) The tripartite structure of the undercoat in initial segments of Purkinje cell axons. Z Anat Entwicklungsgesch 139:1-10.

Cobb SR, Buhl EH, Halasy K, Paulsen O, Somogyi P (1995) Synchronization of neuronal activity in hippocampus by individual GABAergic interneurons. Nature 378:75-78.

Daw MI, Tricoire L, Erdelyi F, Szabo G, McBain CJ (2009) Asynchronous transmitter release from cholecystokinin-containing inhibitory interneurons is widespread and target-cell independent. J Neurosci 29:11112-11122.

Dobó E, Takács VT, Gulyás AI, Nyiri G, Mihály A, Freund TF (2011) New silver-gold intensification method of diaminobenzidine for double-labeling immunoelectron microscopy. J Histochem Cytochem 59:258269.

Eggermann E, Bucurenciu I, Goswami SP, Jonas P (2012) Nanodomain coupling between $\mathrm{Ca}^{2+}$ channels and sensors of exocytosis at fast mammalian synapses. Nat Rev Neurosci 13:7-21.

Ellender TJ, Nissen W, Colgin LL, Mann EO, Paulsen O (2010) Priming of hippocampal population bursts by individual perisomatic-targeting interneurons. J Neurosci 30:5979-5991.

Ferraguti F, Klausberger T, Cobden P, Baude A, Roberts JD, Szucs P, Kinoshita A, Shigemoto R, Somogyi P, Dalezios Y (2005) Metabotropic glutamate receptor 8-expressing nerve terminals target subsets of GABAergic neurons in the hippocampus. J Neurosci 25:10520-10536.

Fiala JC (2005) Reconstruct: a free editor for serial section microscopy. J Microsc 218:52-61.

Freund TF, Katona I (2007) Perisomatic inhibition. Neuron 56:33-42.

Fuentealba P, Begum R, Capogna M, Jinno S, Márton LF, Csicsvari J, Thomson A, Somogyi P, Klausberger T (2008) Ivy cells: a population of nitric-oxide-producing, slow-spiking GABAergic neurons and their involvement in hippocampal network activity. Neuron 57:917-929. 
Földy C, Lee SH, Morgan RJ, Soltesz I (2010) Regulation of fast-spiking basket cell synapses by the chloride channel ClC-2. Nat Neurosci 13:1047-1049.

Földy C, Lee SY, Szabadics J, Neu A, Soltesz I (2007) Cell type-specific gating of perisomatic inhibition by cholecystokinin. Nat Neurosci 10:1128-1130.

Geinisman Y, deToledo-Morrell L, Morrell F, Heller RE, Rossi M, Parshall RF (1993) Structural synaptic correlate of long-term potentiation: formation of axospinous synapses with multiple, completely partitioned transmission zones. Hippocampus 3:435-445.

Glickfeld LL, Scanziani M (2006) Distinct timing in the activity of cannabinoid-sensitive and cannabinoidinsensitive basket cells. Nat Neurosci 9:807-815.

Glickfeld LL, Roberts JD, Somogyi P, Scanziani M (2009) Interneurons hyperpolarize pyramidal cells along their entire somatodendritic axis. Nat Neurosci 12:21-23.

Gonchar Y, Turney S, Price JL, Burkhalter A (2002) Axo-axonic synapses formed by somatostatin-expressing GABAergic neurons in rat and monkey visual cortex. J Comp Neurol 443:1-14.

Gulyás AI, Buzsáki G, Freund TF, Hirase H (2006) Populations of hippocampal inhibitory neurons express different levels of cytochrome c. Eur J Neurosci 23:2581-2594.

Gulyás AI, Szabó GG, Ulbert I, Holderith N, Monyer H, Erdélyi F, Szabó G, Freund TF, Hájos N (2010) Parvalbumin-containing fast-spiking basket cells generate the field potential oscillations induced by cholinergic receptor activation in the hippocampus. J Neurosci 30:15134-15145.

Halasy K, Buhl EH, Lörinczi Z, Tamás G, Somogyi P (1996) Synaptic target selectivity and input of GABAergic basket and bistratified interneurons in the CA1 area of the rat hippocampus. Hippocampus 6:306-329.

Hefft S, Jonas P (2005) Asynchronous GABA release generates long-lasting inhibition at a hippocampal interneuron-principal neuron synapse. Nat Neurosci 8:1319-1328.

Holderith N, Lorincz A, Katona G, Rózsa B, Kulik A, Watanabe M, Nusser Z (2012) Release probability of hippocampal glutamatergic terminals scales with the size of the active zone. Nat Neurosci 15:988-997.

Hájos N, Karlócai MR, Németh B, Ulbert I, Monyer H, Szabó G, Erdélyi F, Freund TF, Gulyás AI (2013) Inputoutput features of anatomically identified CA3 neurons during hippocampal sharp wave/ripple oscillation in vitro. J Neurosci 33:11677-11691.

Iwasaki S, Takahashi T (1998) Developmental changes in calcium channel types mediating synaptic transmission in rat auditory brainstem. J Physiol 509 ( Pt 2):419-423.

Jahn R, Fasshauer D (2012) Molecular machines governing exocytosis of synaptic vesicles. Nature 490:201-207.

Kasugai Y, Swinny JD, Roberts JD, Dalezios Y, Fukazawa Y, Sieghart W, Shigemoto R, Somogyi P (2010) Quantitative localisation of synaptic and extrasynaptic GABAA receptor subunits on hippocampal pyramidal cells by freeze-fracture replica immunolabelling. Eur J Neurosci 32:1868-1888.

Katona I, Sperlágh B, Sík A, Käfalvi A, Vizi ES, Mackie K, Freund TF (1999) Presynaptically located CB1 cannabinoid receptors regulate GABA release from axon terminals of specific hippocampal interneurons. J Neurosci 19:4544-4558.

Katsumaru H, Kosaka T, Heizmann CW, Hama K (1988) Immunocytochemical study of GABAergic neurons containing the calcium-binding protein parvalbumin in the rat hippocampus. Exp Brain Res 72:347-362.

Klausberger T, Somogyi P (2008) Neuronal diversity and temporal dynamics: the unity of hippocampal circuit operations. Science 321:53-57.

Klausberger T, Magill PJ, Márton LF, Roberts JD, Cobden PM, Buzsáki G, Somogyi P (2003) Brain-state- and cell-type-specific firing of hippocampal interneurons in vivo. Nature 421:844-848.

Klausberger T, Marton LF, O'Neill J, Huck JH, Dalezios Y, Fuentealba P, Suen WY, Papp E, Kaneko T, Watanabe M, Csicsvari J, Somogyi P (2005) Complementary roles of cholecystokinin- and parvalbumin-expressing GABAergic neurons in hippocampal network oscillations. J Neurosci 25:97829793.

Kosaka T, Kosaka K, Tateishi K, Hamaoka Y, Yanaihara N, Wu JY, Hama K (1985) GABAergic neurons containing CCK-8-like and/or VIP-like immunoreactivities in the rat hippocampus and dentate gyrus. J Comp Neurol 239:420-430.

Kubota Y, Kawaguchi Y (2000) Dependence of GABAergic synaptic areas on the interneuron type and target size. J Neurosci 20:375-386.

Lapray D, Lasztoczi B, Lagler M, Viney TJ, Katona L, Valenti O, Hartwich K, Borhegyi Z, Somogyi P, Klausberger T (2012) Behavior-dependent specialization of identified hippocampal interneurons. Nat Neurosci 15:1265-1271.

Lasztóczi B, Tukker JJ, Somogyi P, Klausberger T (2011) Terminal field and firing selectivity of cholecystokinin-expressing interneurons in the hippocampal CA3 area. J Neurosci 31:18073-18093.

Lee SY, Soltesz I (2011) Cholecystokinin: a multi-functional molecular switch of neuronal circuits. Dev Neurobiol 71:83-91.

Lieberman AR, Spacek J (1997) Filamentous contacts: the ultrastructure and three-dimensional organization of specialized non-synaptic interneuronal appositions in thalamic relay nuclei. Cell Tissue Res 288:43-57. 
Maccaferri G, Roberts JD, Szucs P, Cottingham CA, Somogyi P (2000) Cell surface domain specific postsynaptic currents evoked by identified GABAergic neurones in rat hippocampus in vitro. J Physiol 524 Pt 1:91-116.

Meinrenken CJ, Borst JG, Sakmann B (2003) Local routes revisited: the space and time dependence of the Ca2+ signal for phasic transmitter release at the rat calyx of Held. J Physiol 547:665-689.

Miles R, Tóth K, Gulyás AI, Hájos N, Freund TF (1996) Differences between somatic and dendritic inhibition in the hippocampus. Neuron 16:815-823.

Mithani S, Atmadja S, Baimbridge KG, Fibiger HC (1987) Neuroleptic-induced oral dyskinesias: effects of progabide and lack of correlation with regional changes in glutamic acid decarboxylase and choline acetyltransferase activities. Psychopharmacology (Berl) 93:94-100.

Nunzi MG, Gorio A, Milan F, Freund TF, Somogyi P, Smith AD (1985) Cholecystokinin-immunoreactive cells form symmetrical synaptic contacts with pyramidal and nonpyramidal neurons in the hippocampus. J Comp Neurol 237:485-505.

Nusser Z, Cull-Candy S, Farrant M (1997) Differences in synaptic GABA(A) receptor number underlie variation in GABA mini amplitude. Neuron 19:697-709.

Nyíri G, Cserép C, Szabadits E, Mackie K, Freund TF (2005) CB1 cannabinoid receptors are enriched in the perisynaptic annulus and on preterminal segments of hippocampal GABAergic axons. Neuroscience 136:811-822.

Palay SL, Sotelo C, Peters A, Orkand PM (1968) The axon hillock and the initial segment. J Cell Biol 38:193201.

Pang ZP, Südhof TC (2010) Cell biology of Ca2+-triggered exocytosis. Curr Opin Cell Biol 22:496-505.

Pawelzik H, Hughes DI, Thomson AM (2002) Physiological and morphological diversity of immunocytochemically defined parvalbumin- and cholecystokinin-positive interneurones in CA1 of the adult rat hippocampus. J Comp Neurol 443:346-367.

Pierce JP, Lewin GR (1994) An ultrastructural size principle. Neuroscience 58:441-446.

Rollenhagen A, Lübke JH (2006) The morphology of excitatory central synapses: from structure to function. Cell Tissue Res 326:221-237.

Rollenhagen A, Sätzler K, Rodríguez EP, Jonas P, Frotscher M, Lübke JH. (2007) Structural determinants of transmission at large hippocampal mossy fiber synapses. J Neurosci. 27(39):10434-44

Rowland KC, Irby NK, Spirou GA. (2000) Specialized synapse-associated structures within the calyx of Held. J Neurosci. 20(24):9135-44

Seal RP, Akil O, Yi E, Weber CM, Grant L, Yoo J, Clause A, Kandler K, Noebels JL, Glowatzki E, Lustig LR, Edwards RH. (2008) Sensorineural deafness and seizures in mice lacking vesicular glutamate transporter 3. Neuron. 57(2):263-75.

Slomianka L, Amrein I, Knuesel I, Sørensen JC, Wolfer DP (2011) Hippocampal pyramidal cells: the reemergence of cortical lamination. Brain Struct Funct.

Sloviter RS (1989) Calcium-binding protein (calbindin-D28k) and parvalbumin immunocytochemistry: localization in the rat hippocampus with specific reference to the selective vulnerability of hippocampal neurons to seizure activity. J Comp Neurol 280:183-196.

Somogyi J, Baude A, Omori Y, Shimizu H, El Mestikawy S, Fukaya M, Shigemoto R, Watanabe M, Somogyi P (2004) GABAergic basket cells expressing cholecystokinin contain vesicular glutamate transporter type 3 (VGLUT3) in their synaptic terminals in hippocampus and isocortex of the rat. Eur $\mathrm{J}$ Neurosci 19:552-569.

Somogyi P (1977) A specific 'axo-axonal' interneuron in the visual cortex of the rat. Brain Res 136:345-350.

Szabadics J, Varga C, Molnár G, Oláh S, Barzó P, Tamás G (2006) Excitatory effect of GABAergic axo-axonic cells in cortical microcircuits. Science 311:233-235.

Szabó GG, Holderith N, Gulyás AI, Freund TF, Hájos N (2010) Distinct synaptic properties of perisomatic inhibitory cell types and their different modulation by cholinergic receptor activation in the CA3 region of the mouse hippocampus. Eur J Neurosci 31:2234-2246.

Takács VT, Freund TF, Nyiri G (2013) Neuroligin 2 is expressed in synapses established by cholinergic cells in the mouse brain. PLoS One 8:e72450.

Taschenberger H, Leão RM, Rowland KC, Spirou GA, von Gersdorff H (2002) Optimizing synaptic architecture and efficiency for high-frequency transmission. Neuron 36:1127-1143.

Telgkamp P, Padgett DE, Ledoux VA, Woolley CS, Raman IM (2004) Maintenance of high-frequency transmission at purkinje to cerebellar nuclear synapses by spillover from boutons with multiple release sites. Neuron 41:113-126.

Tukker JJ, Fuentealba P, Hartwich K, Somogyi P, Klausberger T (2007) Cell type-specific tuning of hippocampal interneuron firing during gamma oscillations in vivo. J Neurosci 27:8184-8189. 
Tukker JJ, Lasztóczi B, Katona L, Roberts JD, Pissadaki EK, Dalezios Y, Márton L, Zhang L, Klausberger T, Somogyi P (2013) Distinct dendritic arborization and in vivo firing patterns of parvalbumin-expressing basket cells in the hippocampal area CA3. J Neurosci 33:6809-6825.

Uchigashima M, Narushima M, Fukaya M, Katona I, Kano M, Watanabe M (2007) Subcellular arrangement of molecules for 2-arachidonoyl-glycerol-mediated retrograde signaling and its physiological contribution to synaptic modulation in the striatum. J Neurosci 27(14):3663-76.

Wilson RI, Nicoll RA (2001) Endogenous cannabinoids mediate retrograde signalling at hippocampal synapses. Nature 410:588-592.

Wilson RI, Kunos G, Nicoll RA (2001) Presynaptic specificity of endocannabinoid signaling in the hippocampus. Neuron 31:453-462.

Wu LG, Westenbroek RE, Borst JG, Catterall WA, Sakmann B (1999) Calcium channel types with distinct presynaptic localization couple differentially to transmitter release in single calyx-type synapses. J Neurosci 19:726-736.

Wyeth MS, Zhang N, Mody I, Houser CR (2010) Selective reduction of cholecystokinin-positive basket cell innervation in a model of temporal lobe epilepsy. J Neurosci 30:8993-9006.

Yoshida T, Uchigashima M, Yamasaki M, Katona I, Yamazaki M, Sakimura K, Kano M, Yoshioka M, Watanabe M (2011) Unique inhibitory synapse with particularly rich endocannabinoid signaling machinery on pyramidal neurons in basal amygdaloid nucleus. Proc Natl Acad Sci U S A 108:30593064. 